\title{
P-TEFb regulation of transcription termination factor Xrn2 revealed by a chemical genetic screen for Cdk9 substrates
}

\author{
Miriam Sansó, ${ }^{1}$ Rebecca S. Levin, ${ }^{2,3}$ Jesse J. Lipp, ${ }^{2,3}$ Vivien Ya-Fan Wang, ${ }^{4}$ Ann Katrin Greifenberg, ${ }^{5}$ \\ Elizabeth M. Quezada, ${ }^{1}$ Akbar Ali, ${ }^{6}$ Animesh Ghosh, ${ }^{6}$ Stéphane Larochelle, ${ }^{1}$ Tariq M. Rana, ${ }^{6,7}$ \\ Matthias Geyer, ${ }^{7}$ Liang Tong, ${ }^{4}$ Kevan M. Shokat, ${ }^{2,3}$ and Robert P. Fisher ${ }^{1}$ \\ ${ }^{1}$ Department of Oncological Sciences, Icahn School of Medicine at Mount Sinai, New York, New York 10029, USA; ${ }^{2}$ Department \\ of Cellular and Molecular Pharmacology, ${ }^{3}$ Howard Hughes Medical Institute, University of California at San Francisco, \\ San Francisco, California 94143, USA; ${ }^{4}$ Department of Biological Sciences, Columbia University, New York, New York 10027, \\ USA; ${ }^{5}$ Department of Structural Immunology, Institute of Innate Immunity, University of Bonn, 53127 Bonn, Germany; \\ ${ }^{6}$ Department of Biochemistry and Molecular Pharmacology, University of Massachusetts Medical School, Worcester, \\ Massachusetts 01605, USA; ${ }^{7}$ Department of Pediatrics, University of California at San Diego School of Medicine, La Jolla, \\ California 92093, USA
}

The transcription cycle of RNA polymerase II (Pol II) is regulated at discrete transition points by cyclin-dependent kinases (CDKs). Positive transcription elongation factor $b$ (P-TEFb), a complex of Cdk9 and cyclin T1, promotes release of paused Pol II into elongation, but the precise mechanisms and targets of Cdk9 action remain largely unknown. Here, by a chemical genetic strategy, we identified $\sim 100$ putative substrates of human P-TEFb, which were enriched for proteins implicated in transcription and RNA catabolism. Among the RNA processing factors phosphorylated by Cdk9 was the 5'-to-3' "torpedo" exoribonuclease Xrn2, required in transcription termination by Pol II, which we validated as a bona fide P-TEFb substrate in vivo and in vitro. Phosphorylation by Cdk9 or phosphomimetic substitution of its target residue, Thr439, enhanced enzymatic activity of Xrn2 on synthetic substrates in vitro. Conversely, inhibition or depletion of Cdk9 or mutation of Xrn2-Thr439 to a nonphosphorylatable Ala residue caused phenotypes consistent with inefficient termination in human cells: impaired Xrn2 chromatin localization and increased readthrough transcription of endogenous genes. Therefore, in addition to its role in elongation, P-TEFb regulates termination by promoting chromatin recruitment and activation of a cotranscriptional RNA processing enzyme, Xrn2.

[Keywords: P-TEFb; RNA polymerase II; Xrn2; chemical genetics; protein phosphorylation; transcription termination] Supplemental material is available for this article.

Received July 31, 2015; revised version accepted November 23, 2015.

In eukaryotes, regulation of gene expression depends on coordination of transcription with mRNA maturation. One integrator of these processes is the C-terminal domain (CTD) of Rpb1, the largest subunit of RNA polymerase II (Pol II). During transcription, multiple cyclin-dependent kinases (CDKs) phosphorylate the CTD, a tandem array of heptad repeats of the sequence $\mathrm{Y}_{1} \mathrm{~S}_{2} \mathrm{P}_{3} \mathrm{~T}_{4} \mathrm{~S}_{5} \mathrm{P}_{6} \mathrm{~S}_{7}$, to recruit factors and enzymes involved in sequential steps of RNA processing (Hsin and Manley 2012).

The CDKs active in transcription play discrete, specialized roles, with little evidence of the plasticity ascribed to CDKs in the cell cycle machinery (Malumbres and Barbacid 2009). For example, Cdk7 (the kinase associated with

Corresponding author: robert.fisher@mssm.edu Article is online at http://www.genesdev.org/cgi/doi/10.1101/gad.269589. 115 . the transcription initiation factor $\mathrm{IIH}$ [TFIIH]) and Cdk9 (the catalytic subunit of positive transcription elongation factor $\mathrm{b}[\mathrm{P}-\mathrm{TEFb}])$ perform essential, nonredundant functions despite their shared substrates and similar distributions on transcribed chromatin (Gomes et al. 2006; Larochelle et al. 2012). Signaling between TFIIH and P$\mathrm{TEFb}$ ensures that they act sequentially; in human cells, the activation of Cdk9 on chromatin, but not its recruitment, requires active Cdk7 (Larochelle et al. 2012). This ordering of functions suggests that distinct CDKs govern

C 2016 Sansó et al. This article is distributed exclusively by Cold Spring Harbor Laboratory Press for the first six months after the full-issue publication date (see http://genesdev.cshlp.org/site/misc/terms.xhtml). After six months, it is available under a Creative Commons License (Attribution-NonCommercial 4.0 International), as described at http:// creativecommons.org/licenses/by-nc/4.0/. 
discrete "phases" of the transcription cycle through unique sets of substrates, analogous to the way different $\mathrm{CDK} /$ cyclin complexes act on targets specific to DNA synthesis $(\mathrm{S})$ phase or mitosis.

The canonical function of P-TEFb is to overcome promoter-proximal Pol II pausing induced by the DRB sensitivity-inducing factor (DSIF; a heterodimer of Spt4 and Spt5) and the negative elongation factor (NELF) (Nechaev and Adelman 2011), recruitment of which depends on Cdk7 (Glover-Cutter et al. 2009; Larochelle et al. 2012). The exact molecular mechanism underlying this switch remains to be determined, but, in vitro, Cdk9 phosphorylates both DSIF and NELF (Kim and Sharp 2001; Fujinaga et al. 2004) in addition to the Ser2, Thr4, Ser5, and Ser7 residues of the Pol II CTD (Ramanathan et al. 2001; Glover-Cutter et al. 2009; Hsin et al. 2011). Phosphorylation by Cdk9 of the Spt5 C-terminal repeat (CTR) regions potentiates the elongation stimulatory activity of DSIF in vitro (Yamada et al. 2006). P-TEFb has also been reported to modify transcriptional activators and coactivators (Alarcon et al. 2009; Dobrovolna et al. 2012) and a component of a histone modification pathway (Shchebet et al. 2012). However, as in the case of pause release, the precise targets and mechanisms through which $\mathrm{P}-\mathrm{TEFb}$ regulates gene expression are largely undefined. Systematic identification of Cdk9 substrates should help to elucidate those mechanisms and determine the division of labor among different CDKs active during the Pol II transcription cycle.

Many of the functions described above were uncovered with mutant CDK variants sensitized to inhibition by bulky, nonhydrolyzable adenine analogs that do not inhibit wild-type kinases. The same active site alteration enables an analog-selective (AS) CDK to use unnatural ATP analogs as phosphate donors and provides a general strategy to identify protein targets - and thus predict functions-of a particular kinase (Alaimo et al. 2001). Here, by a chemical genetic screen, we identified $\sim 100$ potential substrates of human Cdk9 that were enriched for proteins implicated in transcription or processing of RNA. We validated the 5'-to-3' "torpedo" exoribonuclease Xrn2 (Kim et al. 2004b; West et al. 2004; Brannan et al. 2012) as a bona fide Cdk9 substrate. Inhibition or depletion of Cdk9 in human cells diminished Xrn2 phosphorylation on the site identified in the screen. In vitro, phosphorylation by Cdk9 or Asp substitution of the Thr439 residue of Xrn2 enhanced exonucleolytic activity on synthetic substrates. In vivo, Cdk9 inhibition or depletion or a T439A mutation of $X R N 2$ led to increased readthrough transcription consistent with a termination defect. Therefore, in addition to its elongation-promoting function, P-TEFb can directly regulate cotranscriptional events such as termination by phosphorylating components of the relevant RNA processing machineries.

\section{Results}

Identification of Cdk9 substrates

To identify substrates of human P-TEFb, we leveraged the ability of Cdk9 to accommodate bulky ATP analogs after expansion of the active site by mutation of the gatekeeper residue Phe103 to Gly (Larochelle et al. 2012). We tested the activity of purified human $\mathrm{Cdk} 9^{\mathrm{WT}}$ or $\mathrm{Cdk} 9^{\mathrm{F} 103 \mathrm{G}}$ $\left(\mathrm{Cdk}^{\mathrm{as}}\right)$ in complex with cyclin T1 toward the Pol II CTD in the presence of ATP $\gamma S$ or $N^{6}$-substituted analogs. The thiophosphate added to protein substrates was recognized after alkylation with p-nitrobenzylmesylate (PNBM) by anti-thiophosphate ester immunoblotting (Allen et al. 2007). Cdk9 $9^{\mathrm{WT}}$ was able to use ATP $\gamma \mathrm{S}$ but not $N^{6}$. modified $A T P \gamma S$ in vitro. In contrast, $\mathrm{Cdk}^{\text {as }}$ efficiently thiophosphorylated the CTD with $N^{6}$-(phenethyl)-ATP $\gamma \mathrm{S}$ (Supplemental Fig. 1A).

We next sought to identify proteins labeled by exogenous, purified Cdk9 ${ }^{\text {as }}$ with $N^{6}$-(phenethyl)-ATP $\gamma \mathrm{S}$ in total HCT116 cell lysates (Fig. 1A). After incubation, a portion of the reaction was treated with PNBM and analyzed by immunoblotting. We detected labeling above background by $\mathrm{Cdk}^{\text {as }}$ but not Cdk9 $9^{\mathrm{WT}}$, indicating thiophosphorylation of specific substrate proteins (Fig. 1B). The remainder was digested with trypsin without prior alkylation; the resulting thiophosphopeptides were affinity-purified by covalent capture and release, and the liberated phosphopeptides were analyzed by mass spectrometry, as described (Blethrow et al. 2008). The data were filtered to exclude common contaminants based on a combined set of available experimental data from multiple AS kinase substrate capture experiments to yield 295 peptides specifically phosphorylated by $\mathrm{Cdk}^{\text {as }}$, derived from 172 different proteins (Supplemental Table 1).

The majority of phosphorylations occurred at Ser or Thr residues, usually with Pro in the +1 position-the minimal consensus recognition site for CDKs. In addition, Cdk9 preferred Arg at +2 and +3 and Leu in the -1 position relative to the site of phosphorylation (Fig. 1C). Because this consensus sequence closely resembles that of Cdk1 and Cdk2 (pS/T-P-X-K/R) (Songyang et al. 1994), we were concerned about a possible lack of specificity. We therefore compared Cdk9 substrates labeled in HCT116 cell extracts with proteins labeled by similar methods in extracts of different human cell types by $\mathrm{Cdk} 1^{\text {as }} /$ cyclin B1 (Blethrow et al. 2008) or Cdk2 ${ }^{\text {as }}$ /cyclin A2 (Chi et al. 2008). First, we derived a consensus motif from published $\mathrm{Cdk} 1^{\text {as }}$ labeling data (Supplemental Fig. 1B) that was in agreement with one derived from phosphorylation of synthetic peptides by Cdk $1^{\text {WT }}$ (Songyang et al. 1994). Next, we compared Cdk9 and Cdk1 substrate sets and found only five identical peptides, derived from nine proteins in common. A similar comparison between Cdk9 and Cdk2 yielded 11 proteins but only three peptides in common, whereas the overlap between Cdk1 and Cdk2 comprised 30 proteins and 44 peptides (Supplemental Fig. 1C). The minimal overlap between Cdk9 and the cell cycle CDKs indicates that we can reliably distinguish substrate sets of closely related kinases with similar recognition sequences but disparate functions.

We recovered phosphopeptides derived from Cdk9 and cyclin T1, none of which had +1 Pro residues, possibly reflecting relaxed substrate recognition in autophosphorylation. We did not detect phosphorylation of Thr186 in the activation loop of Cdk9. This residue is mostly phosphorylated in Cdk9/cyclin $\mathrm{T} 1$ complexes purified 
A

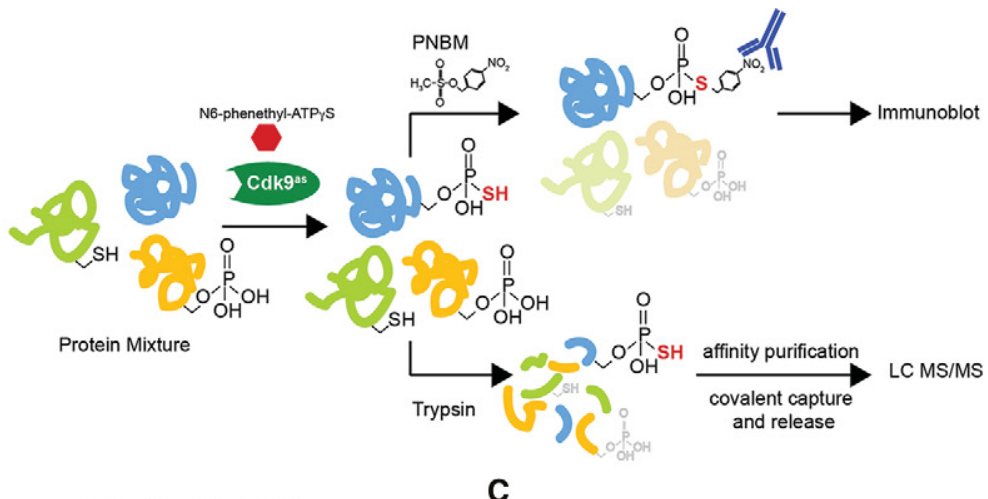

B

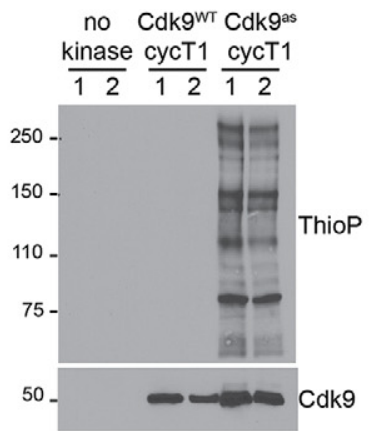

C

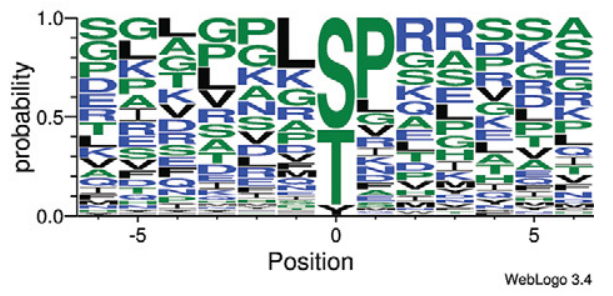

Figure 1. Identification of $\mathrm{P}-\mathrm{TEFb}$ substrates. (A) Schematic diagram of AS labeling and substrate identification protocol. (B) Detection of substrates thiophosphorylated by Cdk9. (Lanes 1,2) Lysates of HCT116 cells were incubated in duplicate with $\mathrm{Cdk} 9^{\mathrm{WT}} /$ cyclin $\mathrm{T} 1, \mathrm{Cdk} 9^{\text {as }} /$ cyclin $\mathrm{T} 1$, or no added kinase, as indicated, in the presence of $N^{6}$-(phenethyl)-ATP $\gamma$ S. After alkylation with PNBM, samples were analyzed by immunoblotting for thiophosphate esters (ThioP) and Cdk9, as indicated. (C) Cdk9 consensus recognition sequence derived from phosphopeptides recovered at least twice in samples incubated with Cdk9 ${ }^{\text {as }}$. (D) Selected gene ontology (GO) terms for Cdk9 substrates. Proteins phosphorylated at S/T-P sites were grouped on the basis of function.

D

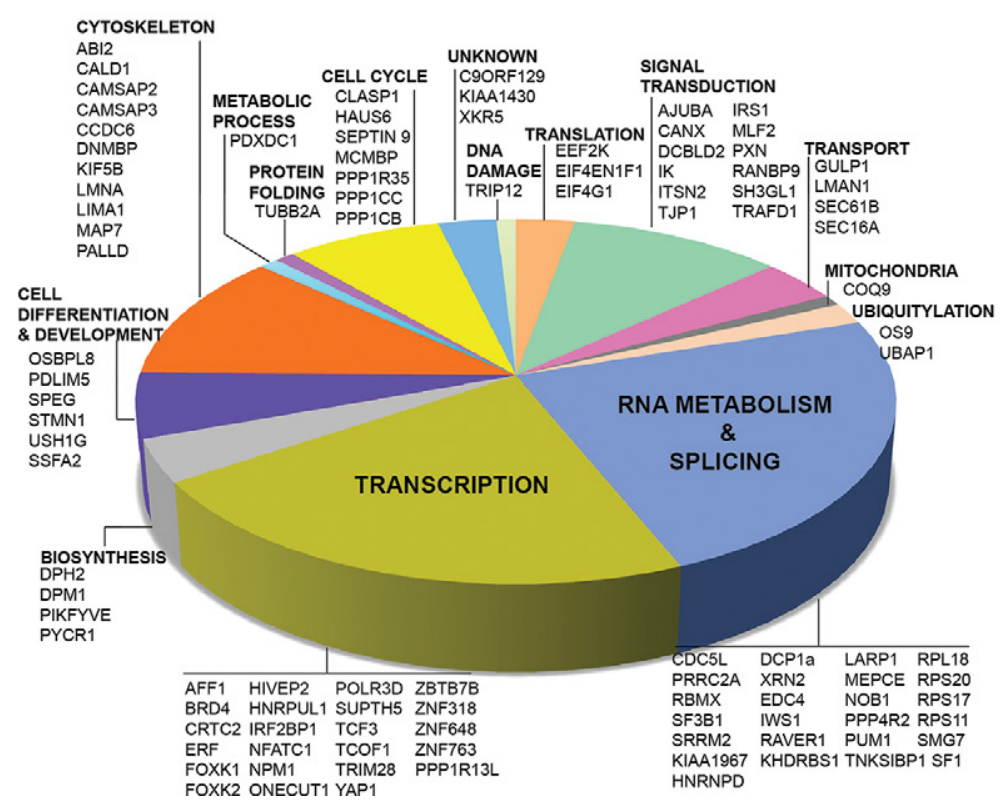

from insect cells (Li et al. 2005; Baumli et al. 2008; Larochelle et al. 2012), but the result is consistent with our previous observation that C $\mathrm{dk} 9$ is incapable of autoactivation (Larochelle et al. 2012).

\section{Cdk9 targets proteins involved in RNA metabolism}

To uncover regulatory roles of P-TEFb, we grouped highconfidence Cdk9 substrates-i.e., those with S/T-P sites-on the basis of function. In cases of proteins implicated in multiple processes, we assigned them to the one most often cited in the literature. Two categories account- ed for $\sim 50 \%$ of the substrates: transcription and RNA metabolism and splicing (Fig. 1D). Unbiased gene ontology (GO) term enrichment corroborated the manual analysis (Supplemental Fig. 1D). Of the previously known or suspected targets, we detected Spt5, BRD4, and AFF1 (Bitoun et al. 2007; Devaiah et al. 2012). We missed Rpb1 (which we previously identified as a $\mathrm{Cdk} 9^{\text {as }}$ substrate in cell extracts by radiolabeling with $N^{6}$-(benzyl)-ATP) (Larochelle et al. 2012), possibly because its CTD has relatively few sites for tryptic cleavage, all of which are in a C-terminal portion that contains degenerate, noncanonical repeats. Therefore, the yield of the unbiased chemical genetic 
screen might still represent only a subset of P-TEFb targets.

The substrate set contained several proteins previously linked functionally or physically to Cdk9: AFF1, which is part of the P-TEFb-containing superelongation complex (SEC) (Lin et al. 2010); the bromodomain-containing protein BRD4, which recruits P-TEFb to chromatin containing acetylated histones (Jang et al. 2005; Yang et al. 2005); and the RNA methylphosphate capping enzyme (MEPCE), which is part of the inhibited 7SK RNA/ HEXIM1/P-TEFb complex (Jeronimo et al. 2007). To perform the labeling, we added purified dimeric $\operatorname{Cdk} 9^{\text {as }}$ / cyclin T1 complexes to whole-cell extracts, so the modification of AFF1, BRD4, and MEPCE in this setting indicates "reconstitution" of these higher-order complexes and a high degree of specificity of P-TEFb in both its protein-protein interactions and phosphorylation reactions.

Cdk9 modified proteins implicated in RNA $5^{\prime}$ end processing, splicing, and transcription termination. Among these was Xrn2, the nuclear 5'-to-3' exoribonuclease required for Pol II termination (Kim et al. 2004b; West et al. 2004). Cdk9 ${ }^{\text {as }}$ also labeled Dcpla and EDC4, noncatalytic subunits of the decapping complex, which severs 7 methyl-guanosine caps from $5^{\prime}$ ends of Pol II transcripts (van Dijk et al. 2002; Fenger-Gron et al. 2005) to generate a $5^{\prime}$ monophosphate end favored by Xrn2 or its cytosolic paralog, Xrn1. Dcpla and EDC4 were previously detected as Xrn2-interacting proteins, as were three other potential Cdk9 substrates: SRRM2, CCDC6, and MEPCE (Brannan et al. 2012). The labeling of multiple proteins thought to work in the same pathway or complex prompted us to investigate a possible connection between $\mathrm{P}-\mathrm{TEFb}$ and termination.

\section{Xrn2 is a CDK substrate}

We generated antibodies specific for the phosphorylated residue Thr439 (Fig. 2A); purified, Escherichia coli-expressed Xrn2 was recognized by the antibody only after phosphorylation in vitro by Cdk9 (Supplemental Fig. 2A). We also tested antibody specificity in extracts of cells depleted of endogenous Xrn2 by expression of shRNA (Brannan et al. 2012) in which we transiently expressed Flag-Xrn2-either wild type, a T439A mutant to mimic the unphosphorylated state, a phosphomimetic T439D mutant, or an E203G mutant that lacks catalytic activity (Fig. 2B). We incubated each immunoprecipitated FlagXrn2 isoform with purified Cdk9/cyclin T1 but detected increased immunoblot signals after $\mathrm{Cdk} 9$ treatment only for the wild-type and E203G variants (Fig. 2C). Therefore, we conclude that (1) the antibody is specific for Xrn2 phosphorylated at Thr439, and (2) Cdk9 phosphorylates Xrn2-Thr439 in vitro.

Next, to ask whether Xrn2 is a specific target of Cdk9 or a general CDK substrate, we measured the activity of purified Cdk7, Cdk12, or Cdk13 (Supplemental Fig. 2B) toward Flag-Xrn2. Cdk12 and Cdk13 form complexes with cyclin $\mathrm{K}$ and are thought to be Ser2 kinases (Bartkowiak et al. 2010) with roles in elongation and 3' end formation (Davidson et al. 2014). The amount of each CDK was
A

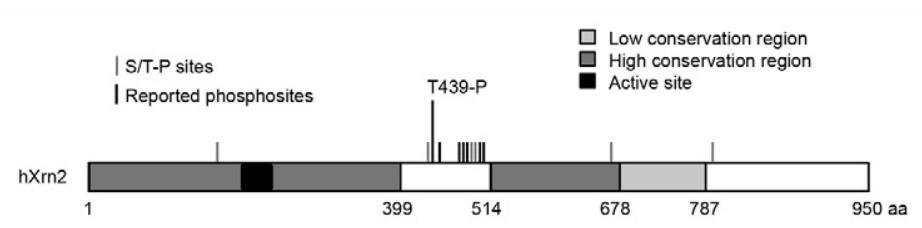

B

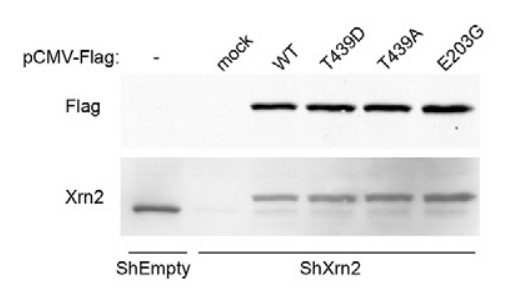

C

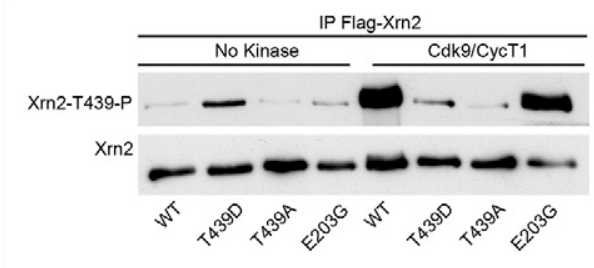

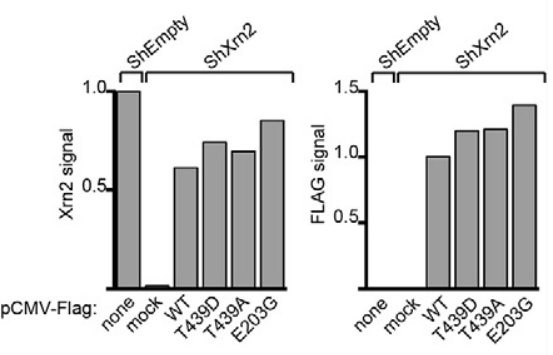

D

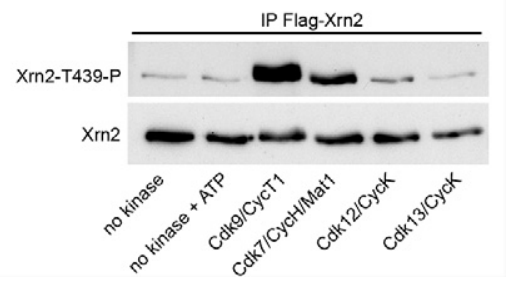

Figure 2. $\mathrm{Xrn} 2$ is a $\mathrm{CDK}$ substrate. $(A)$ Schematic diagram of Xrn2. Reported phosphorylations and potential CDK sites (S/T-P) are indicated with black and gray vertical lines, respectively. $(B)$ Silencing of XRN2 and expression of Flag-tagged wild-type or mutant Xrn2. Immunoblot of equal amounts of protein from cells infected with lentivirus expressing shRNA targeting Xrn2 or a nontargeted control (ShEmpty) with or without expression of Flag-Xrn2 variants: wild type, T439D, T439A, and E203G. Quantification of immunoblot signals is at the right. (C) Xrn2 phosphorylation by Cdk9 on Thr439 in vitro. Flag-Xrn2 (wild type, T439D, T439A, or E203G) was expressed in cells depleted of endogenous Xrn2, immunoprecipitated from cell lysates, and incubated with 100 ng of Cdk9/cyclin T1 or mock-treated, as indicated. Immunoblotting was with phosphospecific (Xrn2-T439-P) or anti-Xrn2 antibodies, as indicated. $(D)$ Phosphorylation of Xrn2-Thr439 by transcriptional CDKs. As in $C$, immunoprecipitated Flag-Xrn $2^{\text {WT }}$ was incubated with the indicated CDK complex in amounts that gave equal phosphorylation of the Rpb1 CTD: $100 \mathrm{ng}$ of Cdk9/cyclin T1, 150 ng of Cdk7/cyclin H/ Mat1, $400 \mathrm{ng}$ of Cdk12/cyclin K, or $500 \mathrm{ng}$ of Cdk13/cyclin K. "No added kinase" controls were performed in the absence or presence of ATP, as indicated. 
normalized based on activity toward the Pol II CTD (Supplemental Fig. 2C; data not shown). Cdk7 phosphorylated Xrn2-Thr439 but was less efficient than Cdk9. There was little or no phosphorylation above background by either Cdk12 or Cdk13 (Fig. 2D). In parallel, we performed kinase assays with radiolabeled ATP and $\mathrm{His}_{6}$-Xrn2(1-782) purified from bacteria. By this measure also, Cdk9 and Cdk7, but not Cdk12 or Cdk13, were Xrn2 kinases (Supplemental Fig. 2D). Xrn2 has 13 S/T-P sites, mostly clustered in the catalytic domain within a linker region that includes Thr439 (Fig. 2A). Mutation of Thr439 reduced but did not abolish phosphorylation by Cdk9 (Supplemental Fig. 2E). The additional sites of phosphorylation are also likely to be in the linker because removal of this region nearly abolished labeling by Cdk9. Phosphorylation of purified Xrn2 by Cdk7 was more strictly dependent on an intact Thr439 residue. Therefore, Thr439 was phosphorylated approximately equally well by Cdk7 and Cdk9 in the context of a purified, truncated Xrn2 expressed in bacteria but preferentially by Cdk9 in full-length FlagXrn2 isolated from human cells.

\section{Phosphorylation of Xrn2 occurs on chromatin and depends on Cak9}

We next asked whether Xrn2 is phosphorylated in vivo at this site. We detected Xrn2-Thr439 phosphorylation exclusively in a low-salt-insoluble fraction enriched for chromatin-associated proteins (Fig. 3A, left panel). When we normalized loading by cell equivalents (i.e., at a fivefold mass excess of soluble proteins), total Xrn2 was roughly equally distributed between soluble and insoluble fractions, but Thr439 phosphorylation was only apparent in the latter (Fig. 3A, right panel). Therefore, Thr439 appears to be modified mainly or exclusively when $\mathrm{Xrn} 2$ is bound to chromatin, consistent with a cotranscriptional function and possible regulation of that function by Cdk9.

To test a possible requirement for $\mathrm{Cdk} 9$ in Xrn2 phosphorylation in vivo, we first treated HCT116 cells with available Cdk9 inhibitors: flavopiridol (FP); 2-fluorophenyl-flavopiridol (2-FP-FP), an FP analog with increased selectivity for Cdk9; or 5,6-dichloro-1- $\beta$-D-ribofuranosylbenzimidazole (DRB) (Marshall et al. 1996; Chao and Price 2001; Ali et al. 2009). In cells treated with $1 \mu \mathrm{M}$ FP or 2-FPFP or $50 \mu M$ DRB for $4 \mathrm{~h}$ prior to harvest, Xrn2-T439-P signals were diminished relative to DMSO-treated controls (Fig. 3B; Supplemental Fig. 3A). Therefore, phosphorylation of Xrn2-Thr439 was acutely sensitive to multiple inhibitors that target Cdk9 in human cells.

In vitro, Xrn2-Thr439 is phosphorylated by either Cdk7 or Cdk9 (Fig. 2D; Supplemental Fig. 2D,E), and Cdk7 is also inhibited by FP (but not by DRB or 2-FP-FP) at the concentrations used in the previous experiment. We therefore asked whether Cdk7 contributes to Xrn2 phosphorylation in vivo by immunoblot analysis of Xrn2T439P after selective inhibition of Cdk7 in CDK $7^{\text {as/as }}$ HCT116 cells (Larochelle et al. 2007). In contrast to results with Cdk9 inhibitors, there was little or no effect on Xrn2-T439P when these cells were treated for $4 \mathrm{~h}$ with $10 \mu \mathrm{M} 3-\mathrm{MB}-\mathrm{PP} 1$, a bulky adenine analog that inhibits $\mathrm{Cdk}^{\text {as }}$ with an $\mathrm{IC}_{50}$ of $\sim 1 \mathrm{nM}$ (Supplemental Fig. 3B), suggesting that the direct contribution of Cdk7 to Xrn2Thr439 phosphorylation in vivo, if any, is minor.

Although FP, 2-FP-FP, and DRB have Cdk9 as a common, primary target and differ in their secondary target profiles, we cannot rule out contributions by other kinases with these drugs alone. There is no $C D K 9^{a s}$ cell line available at present, so, as a complementary, specific test of a Cdk9 requirement in Xrn2 phosphorylation, we depleted Cdk9 in HCT116 cells with shRNA and analyzed target protein phosphorylation (Fig. 3C). In multiple experiments, Cdk9 depletion led to modest reductions, if any, in Pol II CTD Ser2 phosphorylation, consistent with the ability of multiple kinases to generate this modification. To develop a more specific marker of Cdk9 activity, we raised phosphospecific antibodies against two Spt5 residues labeled by Cdk9 ${ }^{\text {as }}$ (Supplemental Table 1): Thr806, within the CTR1 region; and Ser666, located in a region not previously known to harbor Cdk9 phosphorylation
A
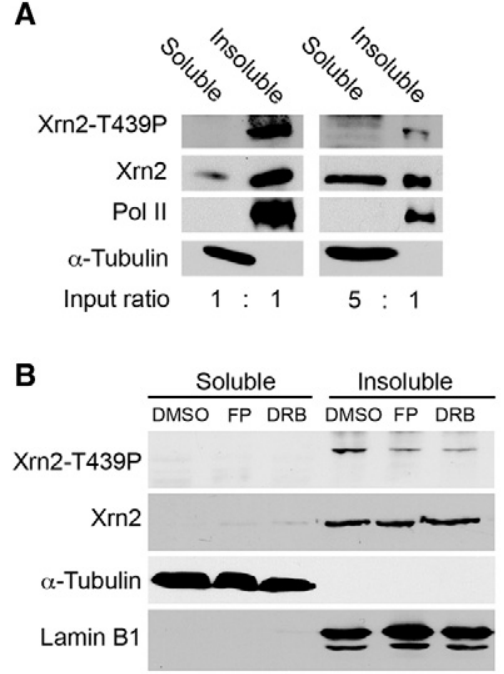

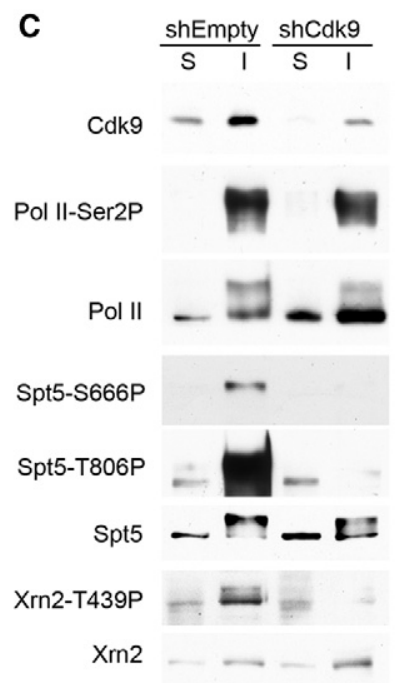

Figure 3. Phosphorylation of Xrn2 occurs on chromatin. (A) Immunoblot analysis of soluble and chromatinassociated protein fractions. Soluble and insoluble proteins were loaded in equal amounts (left panel) or in fivefold excess of soluble protein (right panel). Pol II and $a$-tubulin were controls for insoluble and soluble fractions, respectively. $(B)$ Immunoblot analysis performed as in $A$, (left panel) after $4 \mathrm{~h}$ of treatment with $1 \mu \mathrm{M}$ flavopiridol (FP), $50 \mu \mathrm{M}$ 5,6-dichloro-1- $\beta$-D-ribofuranosyl-benzimidazole (DRB), or DMSO. Lamin B was used as a loading control for the insoluble protein fraction. (C) Depletion of Cdk9 causes loss of Xrn2 and Spt 5 phosphorylation. Extracts of HCT116 cells infected with lentivirus expressing shRNA targeting CDK9 (shCdk9) or empty vector (shEmpty) were fractionated as in $A$ and analyzed by immunoblotting for the indicated proteins. 
sites, between conserved Kyrpides-Ouzounis-Woese (KOW) motifs (Supplemental Fig. 4A). We confirmed antibody specificity in vitro; purified full-length Spt5 expressed in E. coli (Supplemental Fig. 4B) was recognized only after treatment with purified P-TEFb (Supplemental Fig. 4C). Both antibodies recognized proteins of mobility consistent with full-length Spt5 in chromatin-enriched fractions of mock-treated but not Cdk9-depleted HCT116 cells (Fig. 3C). Depletion of Cdk9 likewise diminished phosphorylation of Xrn2-Thr439 without affecting the levels or chromatin association of total Xrn2. Taken together, these results suggest that three residues identified by an unbiased chemical genetic screenSpt5-Ser666, Spt5-Thr806, and Xrn2-Thr439-are specific targets of phosphorylation by Cdk9 in human cells.

\section{Cdk9 activity and Thr439 phosphorylation promote Xrn2 binding to chromatin}

To discern a possible function of Xrn2-Thr439 phosphorylation during the transcription cycle, we first analyzed its distribution by chromatin immunoprecipitation (ChIP). On MYC and CCNB1 (Fig. 4A), Xrn2 binding peaked near the transcription termination site (TTS), but there was also cross-linking to promoter-proximal regions, which was more prominent on CCNB1 (Fig. 4B). ChIP analysis with the anti-Xrn2-T439P antibody also produced peaks over both the transcription start site (TSS) and downstream regions (Fig. 4C). The ChIP signals are specific: Both total Xrn2 and Xrn2-T439P signals were diminished when Xrn2 was depleted with shRNA (Supplemental Fig. 5A,B). We performed a metagene analysis of ChIPseq (ChIP combined with deep sequencing) data reported by Bentley and coworkers (Brannan et al. 2012), which suggested that this bimodal distribution, with peaks over the TSS and TTS, occurs genome-wide (Supplemental Fig. 5C), perhaps consistent with a proposed Xrn2 function in premature termination of divergent transcription.

To ask whether Cdk9 inhibition altered these patterns, we treated cells for 1 or $4 \mathrm{~h}$ with $150 \mathrm{nM} \mathrm{FP}$-treatments that appeared to interfere with P-TEFb function, as indicated by increased Pol II accumulation in promoter-proximal regions and depletion from gene bodies (Fig. 4D). A marker of elongating Pol II, CTD Ser2 phosphorylation (Ser2P), was decreased in the CCNB1 gene body (most clearly at $4 \mathrm{~h}$ ) but obeyed different kinetics on $M Y C$, where it was diminished at $1 \mathrm{~h}$ but recovered by $4 \mathrm{~h}$ of FP treatment (Fig. 4E; Supplemental Fig. 5D). This behavior is consistent with a recent report of selective reactivation of MYC transcription by a BRD4-dependent and $\mathrm{P}-\mathrm{TEFb}$-dependent mechanism in the presence of low to moderate doses of Cdk9 inhibitors (Lu et al. 2015). On both genes at both time points, Xrn2 cross-linking was diminished by FP treatment relative to a DMSO-treated control, particularly in the TTS regions (Fig. 4B). Taken together, these results suggest a requirement for $\mathrm{Cdk} 9$ in Xrn2 recruitment and/or retention. ChIP signals for Xrn2-T439P were also reduced by 150 nM FP (Fig. 4C) disproportionately compared with those of total Xrn2; we observed statistically significant decreases in the ratio of
phospho-Xrn2 to total Xrn2 in termination regions of both genes and in the promoter-proximal region of $M Y C$ (Fig. 4F). Even when Ser2P returned to near pretreatment levels (in downstream regions of $M Y C$ after $4 \mathrm{~h}$ of FP treatment) or at positions where Ser2P is normally low (in promoter-proximal regions), Xrn2-T439P signals were diminished, suggesting that the decrease is not due to loss of Pol II phosphorylation. The effect is specific to Cdk9: Cdk7 inhibition attenuated promoter-proximal Pol II pausing, as previously reported (Larochelle et al. 2012), but had little or no effect on the phospho-Xrn2:total Xrn2 signal ratios on the MYC or CCNB1 genes (Supplemental Fig. 6A,B).

To exclude any confounding effects of Cdk9 inhibitors on Pol II occupancy and test directly whether Thr439 phosphorylation promotes Xrn2 recruitment to chromatin, we performed ChIP analysis of ectopically expressed Flag-Xrn2-wild-type, T439A, or T439D—in cells depleted of endogenous Xrn2 by shRNA. Expression of Flag$\mathrm{Xrn} 2^{\mathrm{WT}}$ generated a ChIP profile on MYC qualitatively similar to that of endogenous Xrn2; peaks and troughs were positioned identically, although the promoter-proximal peak was higher, perhaps due to higher ChIP efficiency with the anti-Flag antibody (Fig. 4, cf. G and B). The T439A variant produced significantly lower signals in both TSS and TTS regions, whereas cross-linking of the T439D mutant did not differ significantly from that of wild-type Flag-Xrn2 (Fig. 4G) even though all three were expressed at similar levels (Fig. 2B). We conclude that phosphorylation of Xrn2 by Cdk9 is likely to contribute directly to its chromatin localization.

\section{Xrn2 phosphorylation enhances enzymatic activity}

Thr439 resides in a poorly conserved insert domain that was disordered in the crystal structure of yeast Xrn2, also known as Rat1 (Xiang et al. 2009). To test whether this residue or its phosphorylation influences enzymatic activity, we measured degradation of a 30-nucleotide (nt) RNA, fluorescently labeled at its $3^{\prime}$ end and hybridized to a 17-nt DNA 5' end-labeled with a fluorescence quencher (Sinturel et al. 2009). Degradation of the RNA to mononucleotides activates the fluorophore, which can be quantified in real time. We first asked whether activity was affected by preincubation of full-length Xrn $2^{\text {WT }}$ with Cdk9. This produced an $\sim 1.5$-fold stimulation, which depended on duration of Cdk9 treatment (Supplemental Fig. 7A) and on ATP, which was not required for Xrn2 activity per se (Supplemental Fig. 7B), but was diminished by $\mathrm{FP}$ addition, indicating a requirement for $\mathrm{Cdk} 9$ catalytic activity (Supplemental Fig. 7C).

These results were consistent with enhancement of Xrn2 activity by Thr439 phosphorylation, but Cdk9 can also modify other sites in the linker. Moreover, full-length Xrn2 was prone to degradation in bacteria, and much of the labeling by Cdk9 occurred on proteolytic fragments that might not be active (data not shown). To circumvent these problems and test directly whether Thr439 influences enzymatic activity, we purified Xrn2 isoforms stabilized by C-terminal truncation (Supplemental Fig. 
A
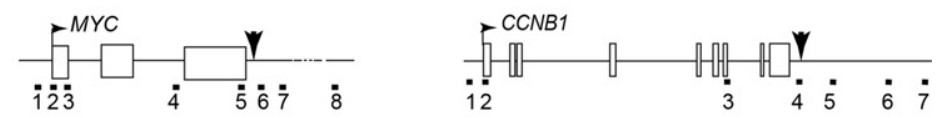

B

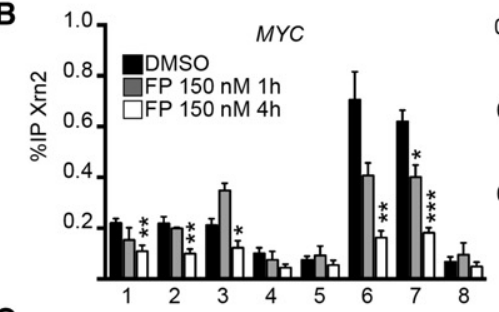

C

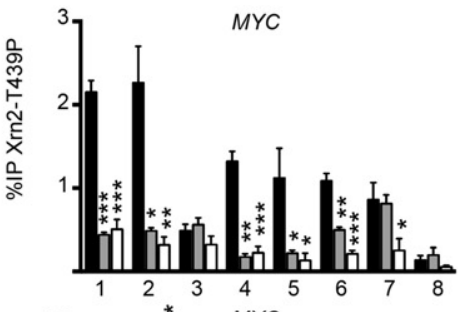

D

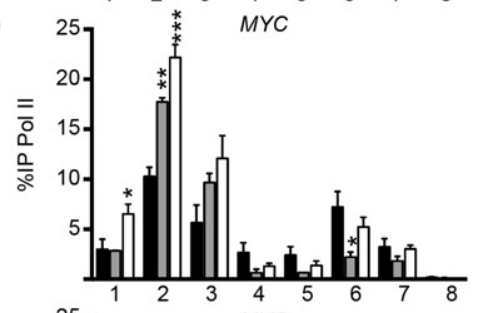

E

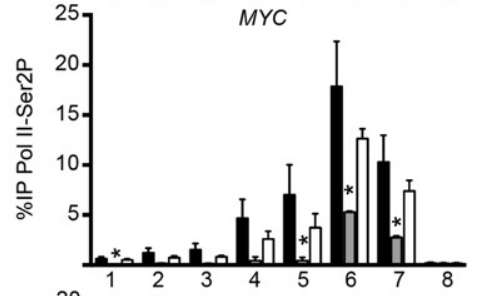

$\mathbf{F}$

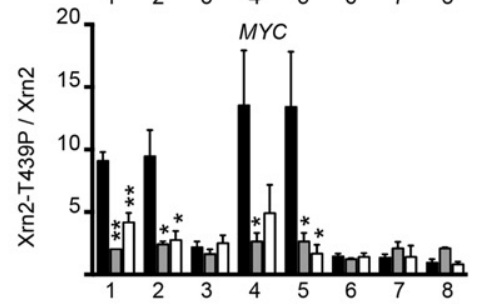

G
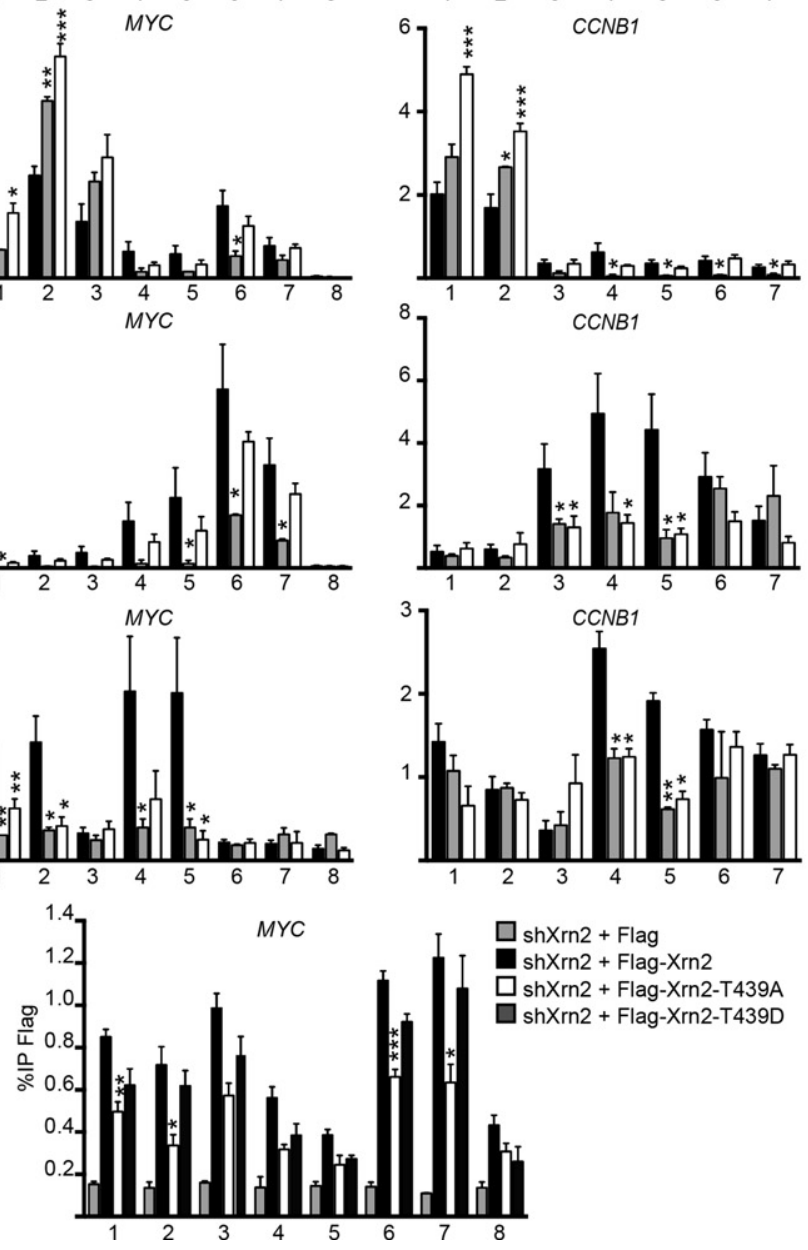

Figure 4. Cdk9 inhibition impairs Xrn2 recruitment to and phosphorylation on chromatin. $(A)$ Schematic diagram of $M Y C$ and CCNB1 genes with positions of the TSS (horizontal arrowhead), polyadenylation site (PAS) (vertical arrowhead), and primers used for ChIP. $(B-E)$ ChIP of Xrn2, Xrn2-T439-P, total Pol II, and Pol II Ser2-P on the MYC or CCNB1 genes in wild-type HCT116 cells treated with DMSO or 150 nM FP for 1 or 4 h. $(F)$ Ratio of Xrn2-T439-P versus total Xrn2 ChIP signals calculated from the data in $B$ and $C$. $(G)$ ChIP of Flag-Xrn2 (wild type, T439A, or T439D) expressed in HCT116 cells depleted of endogenous Xrn2. All graphs show mean of $n=2-6,+$ SEM, and $P$-values $\left([*] P<0.05\right.$; $\left.{ }^{* *}\right] P<0.01$; $\left.\left.{ }^{* * *}\right] P<0.001\right)$ by Student's $t$-test between the indicated FP treatment and DMSO in $B$ or between the indicated mutant and wild type in $G$.

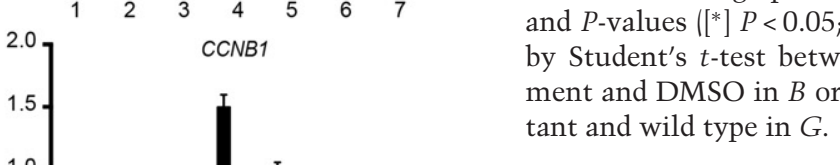

2E): His $_{6}$-Xrn2(1-782) (Xrn2 $\left.\Delta \mathrm{C}\right)$, point mutant variants of $\mathrm{Xrn} 2 \Delta \mathrm{C}$ (E203G, T439A, and T439D), and an internal

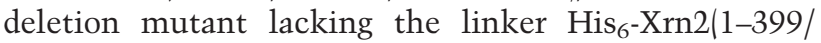
514-782) (-L). Xrn2 activity was nearly abolished by either E203G substitution or removal of the Thr439-containing insert (Fig. 5A). An analogous internal deletion reduced activity of fungal Xrn1 (Chang et al. 2011), indicating a conserved role in catalysis for the linker region.

This analysis revealed a role of Thr439 in enzymatic activity: A T439A mutant was slightly less active than 
Sansó et al.

A

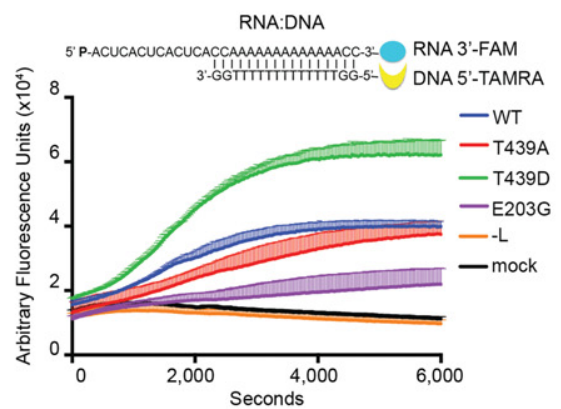

C

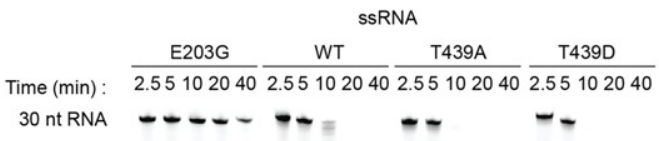

1 nt RNA

D

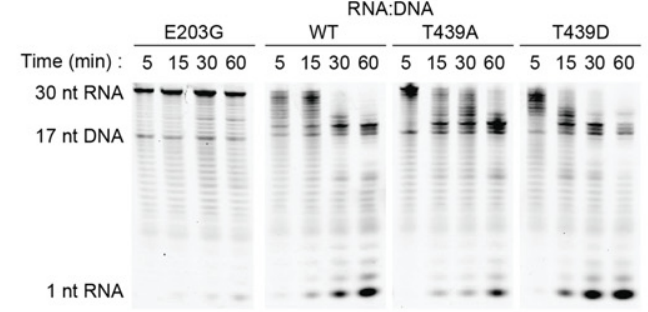

B

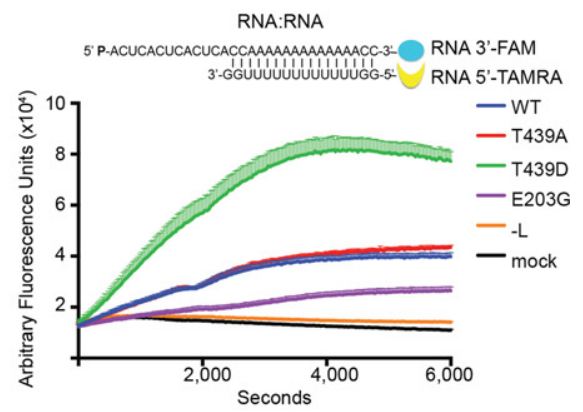

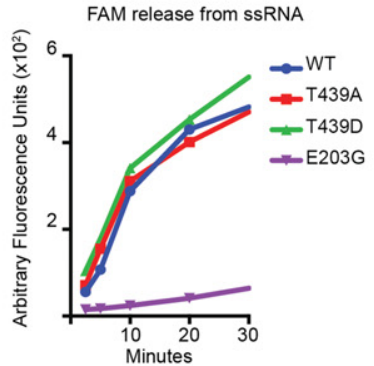

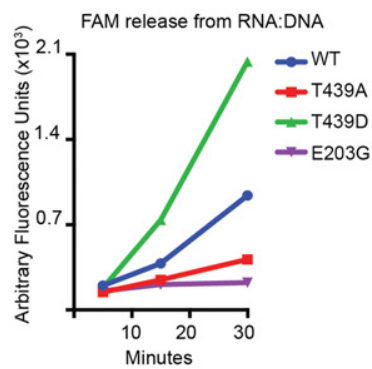

$\mathbf{E}$

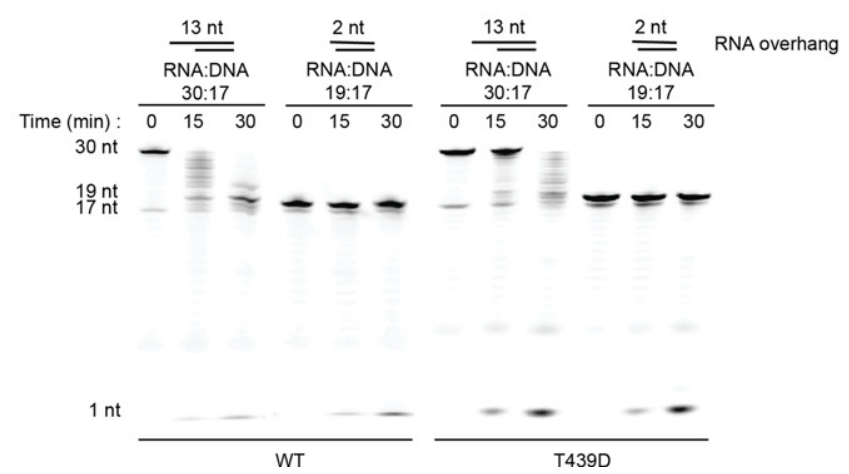

Figure 5. Thr439-to-Asp substitution enhances Xrn2 activity. (A) Exonucleolytic activity of $250 \mathrm{nM}$ Xrn2 $\Delta \mathrm{C}$-wild-type (blue), T439A (red), T439D (green), E203G (purple), and -L (orange)—and mock treatment (black) on 500 nM RNA:DNA substrate (30-nt RNA hybridized to 17-nt DNA). Data were collected in three separate experiments with three different preparations of each enzyme, each performed in duplicate (+SEM). (B) Same as $A$ except that substrate was 30-nt RNA hybridized to 17-nt RNA. (C) Gel-based exonuclease assay of $250 \mathrm{nM}$ Xrn2 $\Delta$ C - wild-type, E203G, -L, T439A, and T439D—on $500 \mathrm{nM} 30$-nt ssRNA substrate. The right panel shows quantification of the released FAM-labeled mononucleotide. $(D)$ Exonuclease assay on 30-nt RNA hybridized to 17-nt DNA substrate, performed as in $C$. $(E)$ Exonuclease assay of Xrn2 $\Delta \mathrm{C}$-wild type and T439D—on 30-nt or 19-nt RNA hybridized to 17-nt DNA, as indicated. Note that a fraction of the 17-nt DNA is degraded through an unknown mechanism and might account for the $\sim 1$-nt fluorescent signal that accumulates even when the RNA cannot be degraded.

$\mathrm{Xrn} 2^{\mathrm{WT}}$, whereas the T439D variant was approximately twice as active (Fig. 5A; Supplemental Fig. 7D). The T439D mutation similarly increased activity on a substrate containing 17 base pairs (bp) of RNA:RNA duplex
(Fig. 5B). These results suggest that Xrn2 activity is stimulated by a negatively charged residue at position 439 . To investigate the mechanism of stimulation, we directly visualized reaction products in sequencing gels. In contrast 
to results with the duplex-containing substrates, the wildtype, T439A, and T439D enzymes were about equally active toward the 30-nt RNA in ssRNA form, whereas E203G and linker deletion mutants were again nearly inactive (Fig. 5C; Supplemental Fig. 7E). This suggested that Thr439 substitutions did not alter catalytic activity per se but rather the ability to negotiate duplex regions, which might be encountered in an RNA with strong secondary structure or a naturally occurring RNA:DNA hybrid (R loop). Indeed, when we analyzed products generated from the RNA:DNA substrate used in the real-time assay (Fig. 5D; Supplemental Fig. 7F), we observed progressive accumulation of $\sim 19$-nt RNA fragments in reactions catalyzed by $\mathrm{Xrn} 2^{\mathrm{WT}}$ and $\mathrm{Xrn} 2^{\mathrm{T} 439 \mathrm{~A}}$, indicating that these isoforms, but not $\mathrm{Xrn} 2^{\mathrm{T} 439 \mathrm{D}}$, were stopped at or near the junction between single-strand and duplex regions.

The impediment to $\mathrm{Xrn} 2^{\mathrm{T} 439 \mathrm{~A}}$ or $\mathrm{Xrn} 2^{\mathrm{WT}}$ entering the duplex region is behavior expected of a distributive enzyme, based on previous analysis of Drosophila Xrn1. In order to begin degrading RNA:DNA hybrids, Xrn1 required $>2 \mathrm{nt}$ of overhanging ssRNA due to its active site architecture-a tunnel $\sim 3$ nt deep with an entrance wide enough for ssRNA but not dsRNA to pass (Jinek et al. 2011). Once initiated on a favorable substrate, however, the intrinsically processive Xrn 1 was able to unwind duplex regions and degrade the RNA to completion. We asked whether human Xrn2 had a similar overhang requirement by comparing activity toward the 30-nt RNA and a 19-nt RNA, both hybridized to the same 17-nt DNA (Fig. 5E). Neither the wild-type nor the T439D form of Xrn2 was able to degrade the shorter RNA, implying an inability to unwind the duplex, as was the case for Xrn1 (Jinek et al. 2011). Although we cannot formally exclude unwinding by a cryptic helicase activity, we consider it unlikely due to the lack of (1) ATP-dependence and (2) fluorophore release in reactions containing $\mathrm{Xrn} 2^{\mathrm{E} 203 \mathrm{G}}$ with a point mutation in the nuclease active site. Taken together, the results suggest that a T439D mutation or phosphorylation by Cdk9 enhances Xrn2 activity to facilitate degradation of substrates with extensive secondary structure, possibly by increasing processivity.

\section{CDKs and Xrn2 phosphorylation promote transcription termination}

To test whether this enhancement contributes to efficient termination in vivo, we first quantified levels of readthrough transcripts by quantitative RT-PCR (qRT-PCR) with primers downstream from the annotated polyadenylation site (PAS) of MYC, FRAT2, or CCNB1, normalized to an amplicon in the body of the same gene (Fig. 6A). To test requirements for Cdk9, we treated cells with $50 \mu \mathrm{M}$ DRB, $150 \mathrm{nM} \mathrm{FP}$, or $150 \mathrm{nM}$ 2-FP-FP for 1 or $4 \mathrm{~h}$; these drugs caused approximately twofold to 10 -fold increases in readthrough transcripts of all three genes (Fig. 6B). As was the case for Ser2P ChIP signals, both total and readthrough MYC transcript levels returned to near the pretreatment baseline after $4 \mathrm{~h}$ of treatment with all three drugs (Fig. 6B; data not shown). At the two other genes that we analyzed or at higher doses of FP or 2-FP-FP 1500
$\mathrm{nM})$, this restoration did not occur; readthrough transcript levels remained elevated even after $4 \mathrm{~h}$ of drug treatment (Fig. 6B; Supplemental Fig. 8A). The effects are Cdk9-specific: When we depleted Cdk9 with shRNA, we likewise detected increases in readthrough transcripts (Fig. 6C), albeit of lower magnitude, possibly reflecting the incomplete knockdown (Fig. 3C). To determine the extent of readthrough transcription after $\mathrm{Cdk} 9$ inhibition, we performed conventional RT-PCR with primer pairs located progressively further downstream from the CCNB1 PAS; $500 \mathrm{nM}$ FP treatment extended the region in which we could detect transcripts by $\sim 2 \mathrm{~kb}$ (Supplemental Fig. 6B). We also tested requirements for $\operatorname{Cdk} 7$, which is required to establish the promoter-proximal pause and activate Cdk9 (Larochelle et al. 2012). Selective inhibition of Cdk7 in CDK7 ${ }^{\text {as/as }}$ HCT116 cells led to more modest, dose-dependent increases in readthrough transcripts of all three genes (Fig. 6D).

The qRT-PCR analysis suggested defects in termination due to inhibition of $\mathrm{Cdk} 9$, but increased steady-state levels of readthrough transcripts would also be consistent with post-transcriptional stabilization of RNAs that are normally rapidly degraded. To quantify nascent transcripts emanating from regions downstream from the PAS relative to the gene body, we isolated nuclei from HCT116 cells treated with $150 \mathrm{nM}$ FP or 2-FP-FP for $1 \mathrm{~h}$ or from DMSO-treated control cells and performed nuclear run-on transcription in the presence of 4-thio-UTP (Davidson et al. 2012). At MYC and FRAT2 (two genes with high steady-state levels of readthrough transcripts after FP or 2-FP-FP treatment) (Fig. 6B), we detected approximately twofold to fourfold increases in nascent readthrough transcripts (Fig. 6E), consistent with a primary defect in termination when Cdk9 is inhibited.

Although the effects of small-molecule inhibitors indicated a requirement for $\mathrm{Cdk} 9$ in termination, they did not establish that Xrn2 is a relevant target. To address this question, we performed qRT-PCR analysis in cells depleted of Xrn2 by shRNA. Under these conditions, we detected increased readthrough transcripts of MYC and FRAT2 (Fig. 6F), consistent with previous reports (West et al. 2004; Mikula et al. 2013). We also saw increased transcription past normal CCNB1 termination signals by conventional PCR-with a forward primer upstream of the PAS and reverse primers at increasing distances downstream-after Xrn2 depletion or CDK inhibition (Supplemental Fig. 8C). Therefore, CDK activity and Xrn2 might be needed for efficient cleavage of the transcript, reminiscent of the Rat1-dependent recruitment of cleavage factors in budding yeast (Luo et al. 2006). Expression of Xrn2 $2^{\text {E203G }}$ exacerbated the readthrough phenotype elicited by shRNA targeting $X R N 2$, suggesting a dominant-negative effect of a catalytically inactive mutant. Expression of $\mathrm{Xrn} 2^{\mathrm{WT}}$ or Xrn $2^{\mathrm{T} 439 \mathrm{D}}$ largely suppressed readthrough transcription induced by the knockdown, whereas Xrn $2^{\mathrm{T} 439 \mathrm{~A}}$ was unable to rescue the defect (Fig. 6F). Taken together, the data suggest that $\mathrm{Cdk} 9$, in addition to its previously defined role in elongation, directly regulates Xrn2 function in transcription termination through phosphorylation of Thr439. 
A

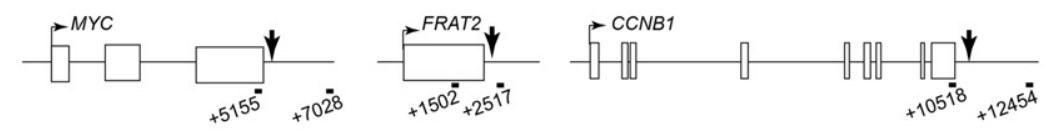

B

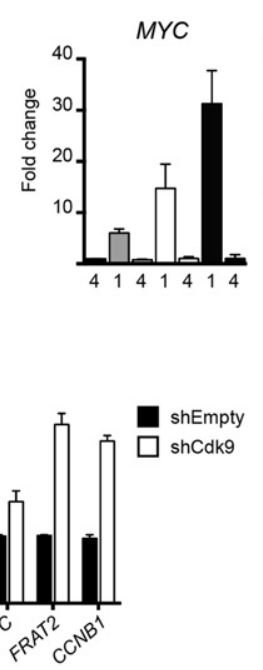

$\mathbf{E}$

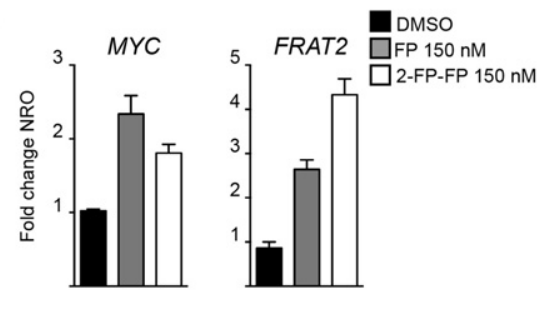

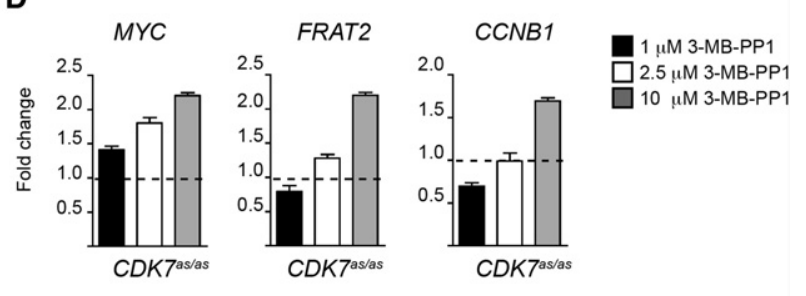

$\mathbf{F}$

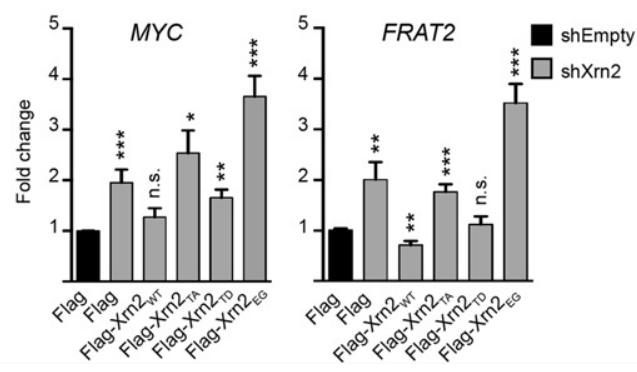

Figure 6. Cdk7, Cdk9, and Xrn2 regulate transcription termination. (A) Schematic representation of MYC, FRAT2, and CCNB1 loci with primer positions relative to the PAS (vertical arrow). Unless otherwise noted, all graphs show mean of $n=3-4,+S E M$. (B) Readthrough transcription after treatment with $150 \mathrm{nM}$ 2-FP-FP, $150 \mathrm{nM} \mathrm{FP}$, or $50 \mu \mathrm{M}$ DRB for 1 or $4 \mathrm{~h}$, expressed as fold change relative to DMSOtreated cells. $(C)$ Readthrough transcription is increased by Cdk9 depletion with shRNA. $(D)$ Readthrough transcription is increased by Cdk7 inhibition. CDK7 ${ }^{\text {as } / a s}$ cells were treated with the indicated concentrations of 3-MB-PP1 for $4 \mathrm{~h}$ and analyzed as in $B$. Readthrough transcription is expressed as fold change relative to DMSO-treated cells (dashed line). (E) Increased nascent RNA synthesis past normal termination signals, detected by nuclear run-on (NRO) transcription in the presence of 4-thio-UTP, in nuclei from cells treated for $1 \mathrm{~h}$ with 150 nM FP or 2-FP-FP. $n=2,+$ SEM. (F) Readthrough transcription is increased by Xrn2 depletion or mutation. Readthrough is rescued by expression of Xrn2 ${ }^{\mathrm{WT}}$ or Xrn2 ${ }^{\mathrm{T} 439 \mathrm{D}}$ but not Xrn2 $2^{\mathrm{T} 439 \mathrm{~A}}$ or Xrn2 ${ }^{\mathrm{E} 203 \mathrm{G}}$. $P$-values are included for each condition compared with cells transfected with empty plasmid (shEmpty). (n.s.) Not significant; $\left.\left(^{*}\right) P<0.05 ;{ }^{* *}\right) P<0.01$; $\left(^{* * *}\right) P<0.001$, by Student's $t$-test.

\section{Discussion}

Targets of P-TEFb revealed by a chemical genetic strategy

Here we report the systematic identification of Cdk9 substrates in a complex protein mixture that preserves important features of biological context; among the labeled proteins were known partners of P-TEFb in higher-order complexes and $\sim 50$ proteins involved in transcription and RNA metabolism. Only a small fraction $(<10 \%)$ is primarily implicated in cell division-the functional category most enriched among substrates of the cell cycle CDKs identified by similar analyses (Blethrow et al. 2008; Chi et al. 2008). This dichotomy is further evidence of specificity, given the similarity in the sequences recognized by Cdk1, Cdk2, and Cdk9. We validated Xrn2 and Spt5 as bona fide substrates: Both were phosphorylated in vivo on chromatin at the same sites labeled by Cdk9 ${ }^{\text {as }}$, two of which were previously detected by proteomics in HeLa cells (Dephoure et al. 2008), and the modifications were diminished upon inhibition or depletion of Cdk9. Finally, mutation of the Xrn2 phosphorylation site that we identified produced transcriptional derangements that were phenocopied by CDK inhibitors.

\section{Cdk9 directly regulates a transcription termination pathway}

This analysis reveals that Cdk9 activity, thought to be rate-limiting for transcription elongation, also regulates a pathway needed for efficient termination. A 
requirement for Xrn2 in termination was the basis for the torpedo model, in which, after transcription past a PAS, the primary transcript is cleaved, but RNA synthesis continues until Xrn2 degrades the downstream fragment and collides with Pol II to induce its dissociation from the template DNA (Kim et al. 2004a; West et al. 2004). The precise mechanism of release remains elusive (Dengl and Cramer 2009; Pearson and Moore 2013).

How termination might be regulated is also obscure, but a linchpin of the torpedo model is the ability of Xrn2 to degrade nascent RNA faster than Pol II synthesizes it. Recently, this model gained support from a demonstration that the termination zone, deduced from genomewide ChIP-seq profiles of Pol II occupancy, could be shifted downstream from the PAS by Xrn2 depletion and simultaneous expression of a dominant-negative mutant (distinct from E203G) or by expression of a "fast" Pol II mutant variant (Fong et al. 2015). Here we provide the reciprocal demonstration that a constitutively "slow" Xrn2-the T439A mutant_failed to rescue termination defects due to Xrn2 depletion in human cells. Our results suggest, moreover, that the effective rate of degradation by Xrn2 can be regulated by Cdk9-dependent phosphorylation of Thr439 (Fig. 7). Previous studies suggested that, compared with Xrn1, Xrn2 orthologs have trouble degrading substrates with extensive double-stranded character (Poole and Stevens 1997; Xiang et al. 2009). Phosphorylation by Cdk9 or a phosphomimetic substitution at Thr439 helps to alleviate this difficulty in vitro, and effects of T439D and T439A mutations on readthrough transcription suggest that this mechanism might operate in vivo.

Unphosphorylated Xrn2-T439

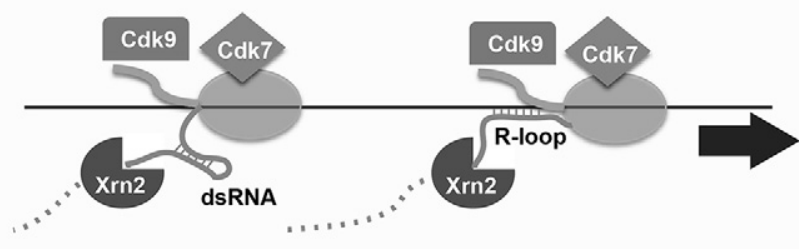

Phosphorylated Xrn2-T439

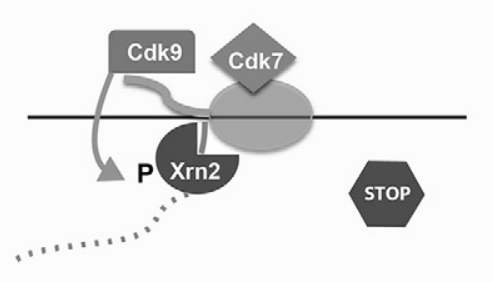

Figure 7. Direct regulation of transcription termination by CDKs. Unphosphorylated Xrn2 is inefficient at degrading RNA within an RNA:DNA hybrid, suggesting difficulty in the processing of naturally occurring secondary structures such as dsRNA or $\mathrm{R}$ loops. A T439D mutation or phosphorylation of Xrn2-Thr439 by Cdk9 enhances Xrn2 activity on such substrates in vitro, possibly through increased processivity, and might support efficient termination of Pol II transcription in vivo.
In vitro, even $\operatorname{Xrn} 2^{\mathrm{T} 439 \mathrm{D}}$ degraded oligoribonucleotides slowly, however, and appeared to pause transiently at the junction between ssRNA and the RNA:DNA duplex. This might be due to the lack of a regulatory subunit; activity of yeast Rat1 toward the same substrate was weaker in the absence of its partner, Rail (Sinturel et al. 2009). Although several Xrn2-associated proteins have been identified (Brannan et al. 2012; Miki et al. 2014), none has yet been shown to perform an analogous stimulatory function. The phosphorylation state of Xrn2 might also influence its recruitment to transcription complexes; Cdk9 inhibitors or T439A mutation impaired Xrn2 cross-linking to chromatin. An interesting possibility is that the two defects might have a single explanation: the inability of unphosphorylated Xrn2 to remain stably associated with RNA substrates.

\section{CDK roles in transcription beyond regulated recruitment}

A principal mechanism by which CDKs influence cotranscriptional events is phosphorylation of the Pol II CTD to recruit factors that regulate elongation, RNA processing, and chromatin modification (Hsin and Manley 2012; Sansó and Fisher 2013). Here we provide evidence for direct regulation of those factors by Cdk9. Effects on binding and phosphorylation of Xrn2 occurred under conditions that preserved Ser2 phosphorylation, which probably depends on Cdk12 and Cdk13 in addition to Cdk9 (Davidson et al. 2014). Consistent with a specific requirement for Cdk9 in Xrn2 regulation, $\mathrm{Cdk} 12$ and $\mathrm{Cdk} 13$, which are $\sim 10$-fold less sensitive than Cdk9 to FP and insensitive to DRB (Bosken et al. 2014), did not phosphorylate Xrn2 in vitro, and deletion of CTK1, which encodes the budding yeast Cdk12 ortholog, did not impair recruitment of Rat 1 (Kim et al. 2004b). Taken together, the results suggest that Cdk9 specifically and directly regulates the recruitment and activation of Xrn2 independent of the Pol II CTD.

The preponderance of transcription and RNA processing factors among the Cdk9 targets that we identified suggests that the direct mode of regulation is prevalent: Future studies are indicated to test roles of Cdk9 in splicing (SF1, SF3B1, SRRM2, and CDC5L) (Kramer 1996; Ajuh et al. 2000) and pause regulation (TRIM28 and YAP1) (Bunch et al. 2014; Estaras et al. 2015; Galli et al. 2015). Moreover, we uncovered Cdk9 phosphorylation sites in catalytic and regulatory subunits of protein phosphatase 1 isoforms, yeast orthologs of which were implicated in cotranscriptional recruitment of cleavage factors (Vanoosthuyse et al. 2014). Recently, activity of DRB-sensitive kinases was reported to prevent premature transcription termination on some genes (Laitem et al. 2015); this suggests that CDKs might regulate $3^{\prime}$ end formation positively or negatively, with the net outcome-readthrough or premature termination-determined by a balance of inputs at specific genes. The apparent restoration of efficient termination despite a persistent deficiency of Xrn2 recruitment at MYC after $4 \mathrm{~h}$ of low-dose FP treatment also implies additional complexity such as redundant termination pathways and might reflect a role for Cdk12 or Cdk13, possibly acting through Ser2P (Davidson et al. 
2014). Finally, we identified components of both active and inhibited P-TEFb complexes as $\mathrm{Cdk} 9$ substrates (AFF1, BRD4, and MEPCE), suggesting potential autoregulatory mechanisms.

In summary, we began with an unbiased chemical genetic search for $\mathrm{Cdk} 9$ substrates and proceeded to define, both biochemically and genetically, a pathway that regulates transcription termination. When Cdk9 was inhibited or phosphorylation of Xrn2-Thr439 was prevented by mutation, readthrough transcription increased at multiple genes. Given the number of potential $\mathrm{P}-\mathrm{TEFb}$ targets implicated in RNA quality control, we expect an even more complex picture of Cdk9 function and regulation to emerge as more of them are validated and characterized.

\section{Materials and methods}

Cell culture, drug treatments, and extract preparation

HCT116 cells were grown as previously described (Larochelle et al. 2012) to $\sim 70 \%-80 \%$ confluence and subjected to drug treatments with 3-MB-PP1, 2-FP-FP (Ali et al. 2009), FP (Sigma), or DRB (EMD). Cells were lysed in RIPA buffer $(50 \mathrm{mM}$ Tris- $\mathrm{HCl}$ at $\mathrm{pH}$ 8.0, $150 \mathrm{mM} \mathrm{NaCl}, 1 \% \mathrm{NP}-40,0.5 \% \mathrm{Na}$-deoxycholate, $0.1 \%$ SDS) plus $2 \mathrm{mM}$ EDTA, $50 \mathrm{mM} \mathrm{NaF}, 1 \mathrm{mM}$ DTT, $1 \mathrm{mM}$ PMSF, and $4 \mu \mathrm{g} / \mathrm{mL}$ leupeptin. Chromatin fractionation was performed as described (Mirzoeva and Petrini 2003).

\section{Kinase assays}

One 15-cm dish of HCT116 cells was transfected with $20 \mu \mathrm{g}$ of plasmid encoding Flag-Xrn2 using Lipofectamine 2000 (Life Technologies). After $24 \mathrm{~h}$, cells were collected and lysed in RIPA buffer. Anti-Flag immunoprecipitates from $1 \mathrm{mg}$ of extract were washed three times with RIPA buffer; once with $25 \mathrm{mM}$ HEPES (pH 7.4), $150 \mathrm{mM} \mathrm{NaCl}, 1 \mathrm{mM}$ DTT, and $1 \mathrm{mM}$ PMSF; and once with kinase buffer (25 mM HEPES at pH 7.4, $10 \mathrm{mM}$ $\mathrm{NaCl}, 10 \mathrm{mM} \mathrm{MgCl}{ }_{2}$ ) and incubated in $30 \mu \mathrm{L}$ of kinase buffer plus $1 \mathrm{mM}$ ATP and the indicated amount of CDK/cyclin for $1 \mathrm{~h}$ at $25^{\circ} \mathrm{C}$, and reactions were terminated by addition of $20 \mathrm{mM}$ EDTA.

\section{Protein thiophosphorylation and phosphopeptide identification}

HCT116 cell extracts prepared in RIPA buffer containing $2 \mathrm{mg}$ of protein were incubated with $0.5 \%(\mathrm{w} / \mathrm{w}) \mathrm{Cdk} 9 /$ cyclin $\mathrm{T} 1$ and 0.1 $\mathrm{mM} N^{6}$-(phenethyl)-ATP $\gamma \mathrm{S}$ in a $300-\mu \mathrm{L}$ reaction volume with final concentrations of $25 \mathrm{mM}$ HEPES (pH 7.4), 30 mM Tris-HCl (pH 8.0), $115 \mathrm{mM} \mathrm{NaCl}$, and $10 \mathrm{mM} \mathrm{MgCl}_{2}$ plus an ATP-regenerating system $(1 \mathrm{mM}$ ATP, $40 \mathrm{mM}$ creatine phosphate, $0.2 \mathrm{mg} / \mathrm{mL}$ creatine phosphokinase). Reactions were carried out for $1 \mathrm{~h}$ at $24^{\circ} \mathrm{C}$ and stopped by addition of $20 \mathrm{mM}$ EDTA. A portion $(2.5 \%)$ was incubated with $50 \mathrm{mM}$ PNBM (Epitomics) for 30 min at $24^{\circ} \mathrm{C}$ and analyzed by immunoblot; the remainder was flash-frozen and thawed, and thiophosphorylated proteins were trypsinized for subsequent analysis as previously described (Blethrow et al. 2008). Two biological replicates with technical duplicates of each were performed. Recovered peptides were analyzed by nanoscale liquid chromatography coupled to a Thermo Orbitrap Velos mass spectrometer, with one technical replicate analyzed by HCD fragmentaion and the other analyzed by ETD fragmentation. Peptide assignments to liquid chromatography- tandem mass spectrometry (LC-MS/MS) data were made against the human Swiss-Prot database using Protein Prospector. Phosphopeptides specific to AS-labeled samples were collated using an in-house R script.

\section{Exonuclease assay}

The indicated amounts of enzyme were incubated at $37^{\circ} \mathrm{C}$ with modified RNA and DNA probes synthesized by IDT Technologies (Supplemental Table 2), as described (Sinturel et al. 2009). Reaction buffer contained $30 \mathrm{mM}$ Tris- $\mathrm{HCl}$ (pH 8.0), $2 \mathrm{mM} \mathrm{MgCl}{ }_{2}$, $50 \mathrm{mM} \mathrm{NH}_{4} \mathrm{Cl}, 0.5 \mathrm{mM} \mathrm{DTT}$, and $20 \mu \mathrm{g} / \mathrm{mL}$ acetylated bovine serum albumin (BSA). Fluorescence due to degradation of RNA to completion was measured in real time in a Synergy $\mathrm{H} 1$ plate reader (BioTek). Products were analyzed in $20 \%$ polyacrylamide gels containing $7 \mathrm{M}$ urea in $45 \mathrm{mM}$ Tris-borate $(\mathrm{pH} 8.3)$ and $1 \mathrm{mM}$ EDTA, scanned on a Typhoon FLA9500 to detect fluorescence, and quantified with ImageQuant TL (GE Healthcare).

\section{RNAi}

pLKO.1-puro shXrn2 (Brannan et al. 2012) and shCdk9 (Dharmacon) shRNA lentivirus (Open Biosystems) were used to infect HCT 116 cells. Knockdowns were selected in $2 \mu \mathrm{g} / \mathrm{mL}$ puromycin for 48 and $72 \mathrm{~h}$, respectively, and verified by immunoblot.

\section{Antibodies}

Anti-phospho-Xrn2 (Thr439) and anti-phospho-Spt5 (Ser666) and (Thr806) were raised against peptides FTPSGIL[pT]PHALGS, VGGFAPM[pS]PRISSP, and PHYGSQ[pT] PLHDGSR, respectively, by 21 st Century Biochemicals. Pol II (sc-899), anti-Spt5 (sc133217), and anti-PP1 (sc-7482) were obtained from Santa Cruz Biotechnology; anti-Ser2P (A300-654A) and anti-Xrn2 (A301103A) were obtained from Bethyl Laboratories; anti- $\alpha$-Tubulin (T6074) and anti-Flag M2 (F1804) were obtained from Sigma; anti-Lamin B1 (ab16048) from Abcam; and anti-thiophosphate ester (2686-1) was obtained from Epitomics.

\section{ChIP}

ChIP was carried out as previously described (Larochelle et al. 2012). qPCR was carried out in an Applied Biosystems ABI7500 instrument with SYBR Green mixes from various manufacturers. Primers for qPCR amplification are listed in Supplemental Table 2

\section{Plasmids}

Inserts to generate pCDFDuet-Xrn2(1-782) and pCMV7.1-3xFlagXrn2 were obtained by PCR amplification from HCT116 cDNA. The pCDFDuet-Xrn2(1-399/514-782) deletion mutant and XRN2 mutants T439A, T439D, and E203G were obtained by QuickChange II XL site-directed mutagenesis (Agilent). For primers, see Supplemental Table 2.

\section{Nuclear run-on transcription}

HCT116 cells $\left(4 \times 10^{6}\right)$ were incubated in lysis buffer $(10 \mathrm{mM}$ Tris$\mathrm{HCl}$ at $\mathrm{pH} 7.5,10 \mathrm{mM} \mathrm{NaCl}, 2.5 \mathrm{mM} \mathrm{MgCl} 2,0.5 \% \mathrm{NP}-40$ ) for 5 min on ice. Nuclei were purified by centrifugation at $400 \mathrm{~g}$ for 4 min, washed in $1 \mathrm{~mL}$ of lysis buffer, and resuspended in $40 \mu \mathrm{L}$ of nucleus storage buffer $(50 \mathrm{mM}$ Tris- $\mathrm{HCl}$ at $\mathrm{pH} 8.3,0.1 \mathrm{mM}$ EDTA, $5 \mathrm{mM} \mathrm{MgCl} 2,40 \%$ glycerol) to which $60 \mu \mathrm{L}$ of reaction mixture $\left(10 \mathrm{mM}\right.$ Tris- $\mathrm{HCl}$ at $\mathrm{pH} 8.3,2.5 \mathrm{mM} \mathrm{MgCl}_{2}, 150 \mathrm{mM}$ $\mathrm{KCl}, 2 \mathrm{mM}$ DTT, $80 \mathrm{U}$ of RNasin [Promega], $0.5 \mathrm{mM}$ 4-thio- 
UTP, 1 mM ATP, 1 mM CTP, 1 mM GTP) was added. Transcription was carried out for $30 \mathrm{~min}$ at $30^{\circ} \mathrm{C}$. Total RNA was extracted with Tripure (Roche) and precipitated with ethanol, resuspended in $30 \mu \mathrm{L}$ of RNase-free water, and quantified. 4-thio-U-containing RNA was biotinylated with $200 \mu \mathrm{g} / \mathrm{mL}$ Biotin-HPDP (Pierce) and purified with Tripure followed by ethanol precipitation. Biotinylated RNA was resuspended in $200 \mu \mathrm{L}$ of RPB buffer $(300 \mathrm{mM}$ $\mathrm{NaCl}, 10 \mathrm{mM}$ Tris- $\mathrm{HCl}$ at $\mathrm{pH} 7.5,5 \mathrm{mM}$ EDTA at $\mathrm{pH}$ 8.0) and affinity-purified with streptavidin-agarose beads. Beads were washed five times in wash buffer $(100 \mathrm{mM}$ Tris- $\mathrm{HCl}$ at $\mathrm{pH} 7.5$, $10 \mathrm{mM}$ EDTA, $1 \mathrm{M} \mathrm{NaCl}, 0.1 \%$ Tween 20), and RNA was eluted in $100 \mu \mathrm{L}$ of $0.1 \mathrm{M} \mathrm{DTT}$ for $15 \mathrm{~min}$ at $24^{\circ} \mathrm{C}$, ethanol-precipitated, and resuspended in $20 \mu \mathrm{L}$ of RNase-free water followed by conversion to cDNA (Maxima Fermentas kit) and qPCR analysis.

\section{RNA extraction and cDNA preparation}

RNA was isolated from cells using Tripure. To synthesize cDNA, $1 \mu \mathrm{g}$ of total RNA and a combination of random hexamers and oligo(dT) were used with Maxima RT according to the manufacturer's protocol (Thermo Scientific). Specific amplicons were assessed by qPCR. For primers see Supplemental Table 2.

\section{Protein purification}

Active $\mathrm{Cdk} 9^{\mathrm{WT}} /$ cyclin $\mathrm{T} 1$ and $\mathrm{Cdk} 9^{\text {as }} /$ cyclin $\mathrm{T} 1$ complexes were purified as described (Larochelle et al. 2012). The trimeric Cdk7 complex was generated by adding purified His-Mat1 to Cdk7/cyclin H (Larochelle et al. 2001). The active Cdk12/cyclin K complex was purified as described (Bosken et al. 2014); the same procedure was used to generate Cdk13(694-1039)/cyclin K. Xrn2(1-782) and Xrn2(1-399/514-782) containing N-terminal $\mathrm{His}_{6}$ tags were expressed in E. coli Rosetta (DE3) (Novagen) for $16 \mathrm{~h}$ at $18^{\circ} \mathrm{C}$ in the presence of $0.2 \mathrm{mM}$ isopropyl- $\beta$-D-thiogalactopyranoside (IPTG; Gold Biotechnology, Inc). Cells were lysed in 20 mM HEPES (pH 7.6), 300 mM NaCl, 0.1\% Triton X-100, 0.5 $\mathrm{mM}$ DTT, and $1 \mathrm{mM}$ AEBSF. The protein was eluted from nickel affinity columns (GE Healthcare) with $300 \mathrm{mM}$ imidazole and purified by size exclusion chromatography in $20 \mathrm{mM}$ HEPES $/ \mathrm{pH}$ 7.6) and $100 \mathrm{mM} \mathrm{NaCl}$, flash-frozen, and stored at $-80^{\circ} \mathrm{C}$ in 20 mM HEPES (pH 7.6), $100 \mathrm{mM} \mathrm{NaCl}, 10 \%$ glycerol, and $1 \mathrm{mM}$ DTT. Full-length Xrn 2 containing an $\mathrm{N}$-terminal His ${ }_{6}$ tag was expressed in E. coli Rosetta (DE3) pLys (Novagen) for $3 \mathrm{~h}$ at $30^{\circ} \mathrm{C}$ in the presence of $0.5 \mathrm{mM}$ IPTG. Cells were lysed in $20 \mathrm{mM}$ HEPES (pH 7.6), $15 \mathrm{mM}$ imidazole, $500 \mathrm{mM} \mathrm{NaCl}, 5 \%$ glycerol, $0.05 \%$ Titron X-100, EDTA-free protease inhibitors tablets (Pierce, 88266), and $1 \mathrm{mM}$ AEBSF. The protein eluted from an FF nickel affinity column (GE Healthcare) with $250 \mathrm{mM}$ imidazole was applied to a Sepharose Q column; eluted with a linear gradient of $0.1-1 \mathrm{M} \mathrm{NaCl}$; dialyzed against $20 \mathrm{mM}$ HEPES (pH 7.6), $50 \mathrm{mM} \mathrm{NaCl}, 10 \%$ glycerol, and $1 \mathrm{mM} \mathrm{DTT}$; and flash-frozen.

\section{Acknowledgments}

We thank members of the Fisher laboratory for helpful discussions, K. Brannan and D. Bentley (University of Colorado) for shRNA constructs targeting Xrn2, P. Tschopp (Harvard Medical School) for Xrn2 ChIP-seq data analysis, and Y. Yamaguchi and H. Handa (Tokyo Institute of Technology) for the DSIF expression plasmids. This work was supported by National Institutes of Health grants GM104291 to R.P.F. and GM090059 to L.T., a Howard Hughes Medical Institute award to K.M.S., and a grant from the Deutsche Forschungsgemeinschaft (GE 976/9-1) to M.G. M.G. is a member of the Deutsche Forschungsgemeinschaft excellence cluster ImmunoSensation. Mass spectrometry was provided by the Bio-Organic Biomedical Mass Spectrometry Resource at University of California at San Francisco supported by National Institutes of Health National Institute of General Medical Sciences 8P41GM103481.

\section{References}

Ajuh P, Kuster B, Panov K, Zomerdijk JC, Mann M, Lamond AI. 2000. Functional analysis of the human CDC5L complex and identification of its components by mass spectrometry. EMBO J 19: 6569-6581.

Alaimo PJ, Shogren-Knaak MA, Shokat KM. 2001. Chemical genetic approaches for the elucidation of signaling pathways. Curr Opin Chem Biol 5: 360-367.

Alarcon C, Zaromytidou AI, Xi Q, Gao S, Yu J, Fujisawa S, Barlas A, Miller AN, Manova-Todorova K, Macias MJ, et al. 2009. Nuclear CDKs drive Smad transcriptional activation and turnover in BMP and TGF- $\beta$ pathways. Cell 139: 757-769.

Ali A, Ghosh A, Nathans RS, Sharova N, O'Brien S, Cao H, Stevenson M, Rana TM. 2009. Identification of flavopiridol analogues that selectively inhibit positive transcription elongation factor (P-TEFb) and block HIV-1 replication. Chembiochem 10: 2072-2080.

Allen JJ, Li M, Brinkworth CS, Paulson JL, Wang D, Hubner A, Chou WH, Davis RJ, Burlingame AL, Messing RO, et al. 2007. A semisynthetic epitope for kinase substrates. Nat Methods 4: 511-516.

Bartkowiak B, Liu P, Phatnani HP, Fuda NJ, Cooper JJ, Price DH, Adelman K, Lis JT, Greenleaf AL. 2010. CDK12 is a transcription elongation-associated CTD kinase, the metazoan ortho$\log$ of yeast Ctk1. Genes Dev 24: 2303-2316.

Baumli S, Lolli G, Lowe ED, Troiani S, Rusconi L, Bullock AN, Debreczeni JE, Knapp S, Johnson LN. 2008. The structure of P-TEFb (CDK9/cyclin T1), its complex with flavopiridol and regulation by phosphorylation. EMBO J 27: 1907-1918.

Bitoun E, Oliver PL, Davies KE. 2007. The mixed-lineage leukemia fusion partner AF4 stimulates RNA polymerase II transcriptional elongation and mediates coordinated chromatin remodeling. Hum Mol Genet 16: 92-106.

Blethrow JD, Glavy JS, Morgan DO, Shokat KM. 2008. Covalent capture of kinase-specific phosphopeptides reveals Cdk1-cyclin B substrates. Proc Natl Acad Sci 105: 1442-1447.

Bosken CA, Farnung L, Hintermair C, Merzel Schachter M, Vogel-Bachmayr K, Blazek D, Anand K, Fisher RP, Eick D, Geyer M. 2014. The structure and substrate specificity of human Cdk12/Cyclin K. Nat Commun 5: 3505.

Brannan K, Kim H, Erickson B, Glover-Cutter K, Kim S, Fong N, Kiemele L, Hansen K, Davis R, Lykke-Andersen J, et al. 2012. mRNA decapping factors and the exonuclease Xrn2 function in widespread premature termination of RNA polymerase II transcription. Mol Cell 46: 311-324.

Bunch H, Zheng X, Burkholder A, Dillon ST, Motola S, Birrane G, Ebmeier CC, Levine S, Fargo D, Hu G, et al. 2014. TRIM28 regulates RNA polymerase II promoter-proximal pausing and pause release. Nat Struct Mol Biol 21: 876-883.

Chang JH, Xiang S, Xiang K, Manley JL, Tong L. 2011. Structural and biochemical studies of the $5^{\prime} \rightarrow 3^{\prime}$ exoribonuclease Xrn 1 . Nat Struct Mol Biol 18: 270-276.

Chao SH, Price DH. 2001. Flavopiridol inactivates P-TEFb and blocks most RNA polymerase II transcription in vivo. I Biol Chem 276: 31793-31799.

Chi Y, Welcker M, Hizli AA, Posakony JJ, Aebersold R, Clurman BE. 2008. Identification of CDK2 substrates in human cell lysates. Genome Biol 9: R149. 
Davidson L, Kerr A, West S. 2012. Co-transcriptional degradation of aberrant pre-mRNA by Xrn2. EMBO J 31: 2566-2578.

Davidson L, Muniz L, West S. 2014. 3' end formation of premRNA and phosphorylation of Ser2 on the RNA polymerase II CTD are reciprocally coupled in human cells. Genes DeV 28: 342-356.

Dengl S, Cramer P. 2009. Torpedo nuclease Rat1 is insufficient to terminate RNA polymerase II in vitro. I Biol Chem 284: 21270-21279.

Dephoure N, Zhou C, Villen J, Beausoleil SA, Bakalarski CE, Elledge SJ, Gygi SP. 2008. A quantitative atlas of mitotic phosphorylation. Proc Natl Acad Sci 105: 10762-10767.

Devaiah BN, Lewis BA, Cherman N, Hewitt MC, Albrecht BK, Robey PG, Ozato K, Sims RJ III, Singer DS. 2012. BRD4 is an atypical kinase that phosphorylates serine2 of the RNA polymerase II carboxy-terminal domain. Proc Natl Acad Sci 109: 6927-6932.

Dobrovolna J, Chinenov Y, Kennedy MA, Liu B, Rogatsky I. 2012. Glucocorticoid-dependent phosphorylation of the transcriptional coregulator GRIP1. Mol Cell Biol 32: 730-739.

Estaras C, Benner C, Jones KA. 2015. SMADs and YAP compete to control elongation of $\beta$-catenin:LEF-1-recruited RNAPII during hESC differentiation. Mol Cell 58: 780-793.

Fenger-Gron M, Fillman C, Norrild B, Lykke-Andersen J. 2005. Multiple processing body factors and the ARE binding protein TTP activate mRNA decapping. Mol Cell 20: 905-915.

Fong N, Brannan K, Erickson B, Kim H, Cortazar MA, Sheridan RM, Nguyen T, Karp S, Bentley DL. 2015. Effects of transcription elongation rate and Xrn2 exonuclease activity on RNA polymerase II termination suggest widespread kinetic competition. Mol Cell 60: 256-267.

Fujinaga K, Irwin D, Huang Y, Taube R, Kurosu T, Peterlin BM. 2004. Dynamics of human immunodeficiency virus transcription: P-TEFb phosphorylates RD and dissociates negative effectors from the transactivation response element. Mol Cell Biol 24: 787-795.

Galli GG, Carrara M, Yuan WC, Valdes-Quezada C, Gurung B, Pepe-Mooney B, Zhang T, Geeven G, Gray NS, de Laat W, et al. 2015. YAP drives growth by controlling transcriptional pause release from dynamic enhancers. Mol Cell 60: 328-337.

Glover-Cutter K, Larochelle S, Erickson B, Zhang C, Shokat K, Fisher RP, Bentley DL. 2009. TFIIH-associated Cdk7 kinase functions in phosphorylation of C-terminal domain Ser7 residues, promoter-proximal pausing, and termination by RNA polymerase II. Mol Cell Biol 29: 5455-5464.

Gomes NP, Bjerke G, Llorente B, Szostek SA, Emerson BM, Espinosa JM. 2006. Gene-specific requirement for P-TEFb activity and RNA polymerase II phosphorylation within the p53 transcriptional program. Genes Dev 20: 601-612.

Hsin JP, Manley JL. 2012. The RNA polymerase II CTD coordinates transcription and RNA processing. Genes Dev 26: 2119-2137.

Hsin JP, Sheth A, Manley JL. 2011. RNAP II CTD phosphorylated on threonine- 4 is required for histone mRNA $3^{\prime}$ end processing. Science 334: 683-686.

Jang MK, Mochizuki K, Zhou M, Jeong HS, Brady JN, Ozato K. 2005. The bromodomain protein Brd4 is a positive regulatory component of P-TEFb and stimulates RNA polymerase II-dependent transcription. Mol Cell 19: 523-534.

Jeronimo C, Forget D, Bouchard A, Li Q, Chua G, Poitras C, Therien C, Bergeron D, Bourassa S, Greenblatt J, et al. 2007. Systematic analysis of the protein interaction network for the human transcription machinery reveals the identity of the 7SK capping enzyme. Mol Cell 27: 262-274.
Jinek M, Coyle SM, Doudna JA. 2011. Coupled 5' nucleotide recognition and processivity in Xrn1-mediated mRNA decay. Mol Cell 41: 600-608.

Kim JB, Sharp PA. 2001. Positive transcription elongation factor B phosphorylates hSPT5 and RNA polymerase II carboxyl-terminal domain independently of cyclin-dependent kinase-activating kinase. J Biol Chem 276: 12317-12323.

Kim M, Ahn SH, Krogan NJ, Greenblatt JF, Buratowski S. 2004a. Transitions in RNA polymerase II elongation complexes at the $3^{\prime}$ ends of genes. EMBO / 23: 354-364.

Kim M, Krogan NJ, Vasiljeva L, Rando OJ, Nedea E, Greenblatt JF, Buratowski S. 2004b. The yeast Rat1 exonuclease promotes transcription termination by RNA polymerase II. Nature 432: 517-522.

Kramer A. 1996. The structure and function of proteins involved in mammalian pre-mRNA splicing. Annu Rev Biochem 65: 367-409.

Laitem C, Zaborowska J, Isa NF, Kufs J, Dienstbier M, Murphy S. 2015. CDK9 inhibitors define elongation checkpoints at both ends of RNA polymerase II-transcribed genes. Nat Struct Mol Biol 22: 396-403.

Larochelle S, Chen J, Knights R, Pandur J, Morcillo P, ErdjumentBromage H, Tempst P, Suter B, Fisher RP. 2001. T-loop phosphorylation stabilizes the CDK7-cyclin H-MAT1 complex in vivo and regulates its CTD kinase activity. $E M B O J$ 20: 3749-3759.

Larochelle S, Merrick KA, Terret ME, Wohlbold L, Barboza NM, Zhang C, Shokat KM, Jallepalli PV, Fisher RP. 2007. Requirements for Cdk7 in the assembly of Cdk1/cyclin B and activation of Cdk2 revealed by chemical genetics in human cells. Mol Cell 25: 839-850.

Larochelle S, Amat R, Glover-Cutter K, Sanso M, Zhang C, Allen IJ, Shokat KM, Bentley DL, Fisher RP. 2012. Cyclin-dependent kinase control of the initiation-to-elongation switch of RNA polymerase II. Nat Struct Mol Biol 19: 1108-1115.

Li Q, Price JP, Byers SA, Cheng D, Peng J, Price DH. 2005. Analysis of the large inactive P-TEFb complex indicates that it contains one 7SK molecule, a dimer of HEXIM1 or HEXIM2, and two P-TEFb molecules containing Cdk9 phosphorylated at threonine 186. J Biol Chem 280: 28819-28826.

Lin C, Smith ER, Takahashi H, Lai KC, Martin-Brown S, Florens L, Washburn MP, Conaway JW, Conaway RC, Shilatifard A. 2010. AFF4, a component of the ELL/P-TEFb elongation complex and a shared subunit of MLL chimeras, can link transcription elongation to leukemia. Mol Cell 37: 429-437.

Lu H, Xue Y, Yu GK, Arias C, Lin J, Fong S, Faure M, Weisburd B, Ji X, Mercier A, et al. 2015. Compensatory induction of MYC expression by sustained CDK9 inhibition via a BRD4-dependent mechanism. Elife 4: e06535.

Luo W, Johnson AW, Bentley DL. 2006. The role of Rat1 in coupling mRNA 3 -end processing to transcription termination: implications for a unified allosteric-torpedo model. Genes Dev 20: 954-965.

Malumbres M, Barbacid M. 2009. Cell cycle, CDKs and cancer: a changing paradigm. Nat Rev Cancer 9: 153-166.

Marshall NF, Peng J, Xie Z, Price DH. 1996. Control of RNA polymerase II elongation potential by a novel carboxyl-terminal domain kinase. J Biol Chem 271: 27176-27183.

Miki TS, Richter H, Ruegger S, Grosshans H. 2014. PAXT-1 promotes XRN2 activity by stabilizing it through a conserved domain. Mol Cell 53: 351-360.

Mikula M, Bomsztyk K, Goryca K, Chojnowski K, Ostrowski J. 2013. Heterogeneous nuclear ribonucleoprotein (HnRNP) $\mathrm{K}$ genome-wide binding survey reveals its role in regulating 
3'-end RNA processing and transcription termination at the early growth response 1 (EGR1) gene through XRN2 exonuclease. J Biol Chem 288: 24788-24798.

Mirzoeva OK, Petrini JH. 2003. DNA replication-dependent nuclear dynamics of the Mre11 complex. Mol Cancer Res 1: 207-218.

Nechaev S, Adelman K. 2011. Pol II waiting in the starting gates: regulating the transition from transcription initiation into productive elongation. Biochim Biophys Acta 1809: 34-45.

Pearson EL, Moore CL. 2013. Dismantling promoter-driven RNA polymerase II transcription complexes in vitro by the termination factor Rat1. I Biol Chem 288: 19750-19759.

Poole TL, Stevens A. 1997. Structural modifications of RNA influence the $5^{\prime}$ exoribonucleolytic hydrolysis by XRN1 and HKE1 of Saccharomyces cerevisiae. Biochem Biophys Res Commun 235: 799-805.

Ramanathan Y, Rajpara SM, Reza SM, Lees E, Shuman S, Mathews MB, Pe'ery T. 2001. Three RNA polymerase II carboxylterminal domain kinases display distinct substrate preferences. J Biol Chem 276: 10913-10920.

Sansó M, Fisher RP. 2013. Modelling the CDK-dependent transcription cycle in fission yeast. Biochem Soc Trans 41: 1660-1665.

Shchebet A, Karpiuk O, Kremmer E, Eick D, Johnsen SA. 2012. Phosphorylation by cyclin-dependent kinase-9 controls ubiquitin-conjugating enzyme-2A function. Cell Cycle 11: 21222127.
Sinturel F, Pellegrini O, Xiang S, Tong L, Condon C, Benard L. 2009. Real-time fluorescence detection of exoribonucleases. RNA 15: 2057-2062.

Songyang Z, Blechner S, Hoagland N, Hoekstra MF, PiwnicaWorms H, Cantley LC. 1994. Use of an oriented peptide library to determine the optimal substrates of protein kinases. Curr Biol 4: 973-982.

van Dijk E, Cougot N, Meyer S, Babajko S, Wahle E, Seraphin B. 2002. Human Dcp2: a catalytically active mRNA decapping enzyme located in specific cytoplasmic structures. EMBO $J$ 21: 6915-6924.

Vanoosthuyse V, Legros P, van der Sar SJ, Yvert G, Toda K, Le Bihan T, Watanabe Y, Hardwick K, Bernard P. 2014. CPFassociated phosphatase activity opposes condensin-mediated chromosome condensation. PLoS Genet 10: e1004415.

West S, Gromak N, Proudfoot NJ. 2004. Human $5^{\prime} \rightarrow 3^{\prime}$ exonuclease Xrn2 promotes transcription termination at co-transcriptional cleavage sites. Nature 432: 522-525.

Xiang S, Cooper-Morgan A, Jiao X, Kiledjian M, Manley JL, Tong L. 2009. Structure and function of the $5^{\prime} \rightarrow 3^{\prime}$ exoribonuclease Rat1 and its activating partner Rail. Nature 458: 784-788.

Yamada T, Yamaguchi Y, Inukai N, Okamoto S, Mura T, Handa H. 2006. P-TEFb-mediated phosphorylation of hSpt5 C-terminal repeats is critical for processive transcription elongation. Mol Cell 21: 227-237.

Yang Z, Yik JH, Chen R, He N, Jang MK, Ozato K, Zhou Q. 2005. Recruitment of P-TEFb for stimulation of transcriptional elongation by the bromodomain protein Brd4. Mol Cell 19: 535-545. 


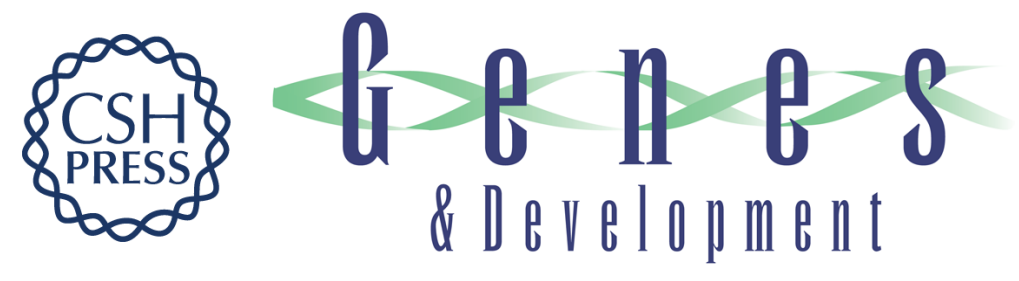

\section{P-TEFb regulation of transcription termination factor Xrn2 revealed by a chemical genetic screen for Cdk9 substrates}

Miriam Sansó, Rebecca S. Levin, Jesse J. Lipp, et al.

Genes Dev. 2016, 30:

Access the most recent version at doi:10.1101/gad.269589.115

Supplemental http://genesdev.cshlp.org/content/suppl/2016/01/04/30.1.117.DC1
Material

References This article cites 64 articles, 29 of which can be accessed free at: http://genesdev.cshlp.org/content/30/1/117.full.html\#ref-list-1

Creative This article is distributed exclusively by Cold Spring Harbor Laboratory Press for the first Commons six months after the full-issue publication date (see

License http://genesdev.cshlp.org/site/misc/terms.xhtml). After six months, it is available under a Creative Commons License (Attribution-NonCommercial 4.0 International), as described at http://creativecommons.org/licenses/by-nc/4.0/.

Email Alerting Receive free email alerts when new articles cite this article - sign up in the box at the top Service right corner of the article or click here.

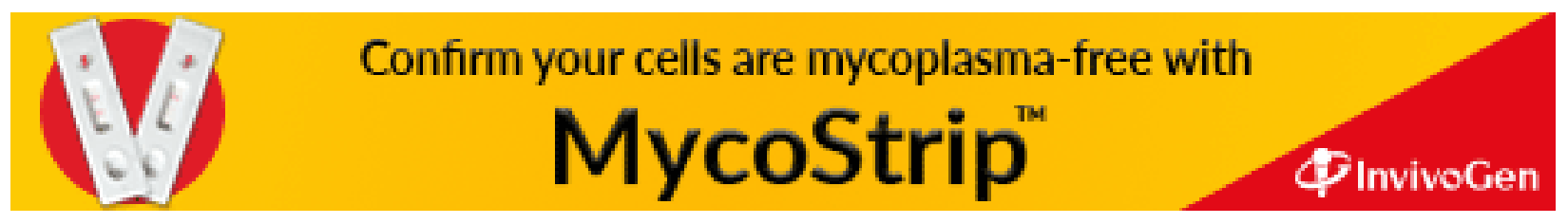

